\title{
Chordin-like 1 is a novel prognostic biomarker and correlative with immune cell infiltration in lung adenocarcinoma
}

\author{
Bing Deng ${ }^{1}$, Xiaorui Chen ${ }^{1}$, Lingfang Xu ${ }^{1}$, Li Zheng ${ }^{1}$, Xiaoqian Zhu ${ }^{1}$, Junwei Shi ${ }^{1}$, Lei Yang ${ }^{1}$, \\ Dian Wang ${ }^{1}$, Depeng Jiang ${ }^{1}$ \\ ${ }^{1}$ Department of Respiratory Medicine, The Second Affiliated Hospital of Chongqing Medical University, \\ Chongqing, China
}

Correspondence to: Depeng Jiang; email: gdp116@hospital.cqmu.edu.cn

Keywords: lung adenocarcinoma, CHRDL1, chordin-like 1, prognosis, TCGA

Received: March 18, $2021 \quad$ Accepted: December 29, $2021 \quad$ Published: January 12, 2022

Copyright: (C) 2022 Deng et al. This is an open access article distributed under the terms of the Creative Commons Attribution License (CC BY 3.0), which permits unrestricted use, distribution, and reproduction in any medium, provided the original author and source are credited.

\section{ABSTRACT}

Chordin-like 1 (CHRDL1), an inhibitor of bone morphogenetic proteins (BMPs), has been recently reported to participate in the progression of numerous tumors, however, its role in lung adenocarcinoma (LUAD) remains unclear. Our study aimed to demonstrate relationship between CHRDL1 and LUAD based on data from The Cancer Genome Atlas (TCGA). Among them, CHRDL1 expression revealed promising power for distinguishing LUAD tissues form normal sample. Low CHRDL1 was correlated with poor clinicopathologic features, including high T stage (OR=0.45, $P<0.001)$, high N stage (OR=0.57, $P<0.003)$, bad treatment effect $(O R=0.64, P=0.047)$, positive tumor status $(O R=0.63, P=0.018)$, and TP53 mutation $(O R=0.49, P<0.001)$. The survival curve illustrated that low CHRDL1 was significantly correlative with a poor overall survival (HR=0.60, $P<0.001)$. At multivariate Cox regression analysis, CHRDL1 remained independently correlative with overall survival. GSEA identified that the CHRDL1 expression was related to cell cycle and immunoregulation. Immune infiltration analysis suggested that CHRDL1 was significantly correlative with 7 kinds of immune cells. Immunohistochemical validation showed that CHRDL1 was abnormally elevated and negatively correlated with Th2 cells in LUAD tissues. In conclusion, CHRDL1 might become a novel prognostic biomarker and therapy target in LUAD. Moreover, CHRDL1 may improve the effectiveness of immunotherapy by regulating immune infiltration.

\section{INTRODUCTION}

Lung cancer remains the malignant tumor with the highest mortality around the world and has seriously burdened our health and economics for a long time [1, 2]. Non-small cell lung cancer (NSCLC) is the largest category of lung cancer and accounts for $80 \%-85 \%$ of the total lung cancer. Among them, lung adenocarcinoma (LUAD) is the most common subtype of NSCLC [3]. Patients with early LUAD do not have specific symptoms, so they often progress to advanced patients at the time of diagnosis. There are many therapy methods for advanced patients in LUAD, including chemotherapy, radiotherapy, targeted therapy and immunotherapy [4]. In the past ten years, targeted therapy has made significant progress in lung cancer
[5]. Several genes have been applied as drug targets, such as epidermal growth factor receptor (EGFR), anaplastic lymphoma kinase (ALK), ROS1, RET, HER2, Kras and MET [6-8]. Drugs explored based on these genes have shown exciting efficacy [9]. However, due to the high heterogeneity, complexity and progression of cancer, the available biological targets are not satisfactory [10]. Thus, it is vital to continually identify more efficient prognostic biomarkers and other potential therapy targets [11].

CHRDL1 (Chordin-like 1) is a kind of secretory protein belonging to the Chordin family [12]. Its function is similar to that of Chordin, mainly as a specific inhibitor of bone morphogenetic proteins (BMPs) [13]. The initial study suggested that CHRDL1 played an 
essential role in anterior segment development and cortical neuronal development $[14,15]$. Recently, researchers found that CHRDL1 could participate in the progression of several tumors, such as malignant melanoma, leukemia, breast cancer and gastric cancer [16-19]. Moreover, the prognostic value of CHRDL1 has also been mentioned recently. In breast cancer and thyroid cancer, patients with high CHRDL1 had a poorer prognosis [20, 21]. However, its role of CHRDL1 in LUAD remains unclear.

Our study performed the differential expression of CHRDL1 between LUAD patients and normal samples based on the TCGA database. The association between CHRDL1 and clinicopathologic features was evaluated, as well as the prognostic significance. Then it was grouped according to its expression level. And Function of clustering and enrichment of pathways of CHRDL1 were used to expound the underlying mechanism in LUAD by GO, KEGG and GSEA analysis. Moreover, we comprehensively discuss the possible influence of CHRDL1 on immunotherapy through analyzing the relevance between CHRDL1 and immune infiltration. Finally, experimental verification identified the specific expression of CHRDL1 and favorable prognostic value in LUAD.

\section{MATERIALS AND METHODS}

\section{RNA-sequencing profiles containing clinic data from TCGA and GTEx data repository}

A total of 513 cases of gene expression profile (HTSeqFPKM and HTSeq-counts) containing clinical data from LUAD projects were collected from TCGA. Whether it contained clinical data as the exclusion criteria in this study. And transcripts per million reads (TPM) transformed from level 3 HTSeq-FPKM profiles were used for the subsequent analyses. Unavailable or unknown clinical characteristics in 513 patients were considered as missing values [22]. All the displayed analysis adopted the value of $\log _{2}(\mathrm{TPM}+1)$. The operating guidelines stated by TCGA (https://www. cancer.gov/tcga) were strictly implemented. The RNAseq data for differential expression and pan-cancer analysis were obtained from UCSC XENA (https://xenabrowser.net/datapages/). The Toil process was regarded as a unified processing program to obtain TCGA and GTEx data in TPM format [23].

\section{Screening of significant DEGs (differential expression genes) based on CHRDL1 in LUAD}

DESeq2 (3.8) package was applied to screen the significant DEGs based on CHRDL1 expression in LUAD [24]. The threshold values for the DEGs were set as $\mid \log 2$ (Fold Change) $\mid>1.5$ and adjusted $\mathrm{P}$ value $<0.05$.

\section{GO and KEGG enrichment analysis}

ClusterProfiler (3.6.0) software was implemented to perform GO function and KEGG pathway enrichment analysis on the DEGs in high/low CHRDL1 expression group respectively [25].

\section{Gene set enrichment analysis (GSEA)}

In the study, GSEA, conducted by $\mathrm{R}$ package clusterProfiler (3.6.0), was used to illuminate the differences of functional clustering and enrichment pathways between high and low CHRDL1 groups [26]. The gene set permutations in each analysis were set as 1000 times. A phenotype label was generated according to the expression level of CHRDL1. And the pathways enrichment of MSigDB Collection (c2.cp.v7.0.symbols.gmt) were performed based on adjusted $P$ value $<0.05$ and FDR q-value $<0.25$.

\section{The correlation between CHRDL1 expression and immune infiltration}

Single-sample gene set enrichment analysis (ssGSEA) method was applied for the immune infiltration analysis in LUAD. And the GSVA package of R (3.6.0) was used to calculated for 24 types of immune cells in tumors, including $\mathrm{B}$ cells, $\mathrm{T}$ cells, CD8 $\mathrm{T}$ cells, natural killer (NK) cells [27], CD56bright natural killer cells (NK CD56bright cells), CD56dim natural killer cells (NK CD56dim cells), regulatory $\mathrm{T}$ cells (Treg), central memory $\mathrm{T}$ cells $(\mathrm{Tcm})$, effector memory $\mathrm{T}$ cells $(\mathrm{Tem})$, gamma delta $\mathrm{T}$ cells (Tgd), $\mathrm{T}$ follicular helper (Tfh), dendritic cells (DCs), immature dendritic cells (iDCs), activated dendritic cells (aDCs), plasmacytoid dendritic cells (pDCs), mast cells [28], neutrophils, eosinophils, macrophages, cytotoxic cells, $\mathrm{T}$ helper cells, type- $1 \mathrm{~T}$ helper cells (Th1), type-2 T helper cells (Th2), and type17 helper cells (Th17) [29, 30]. According to the signature genes of 24 types immunocytes in the literature [31], the gene expression data of each tumor sample was used to quantify the relative enrichment score of every immunocyte. Spearman correlation was used to analyze the relationship between CHRDL1 and these immune cells, and the differences of immune cell infiltration between the high and low CHRDL1 expression groups were analyzed by Wilcoxon rank sum test.

\section{Establishment of protein-protein interaction (PPI) network}

PPI network of DEGs based on CHRDL1 expression was established by String online database (http://string-db.org), 
and the filter criteria was the interaction with combined $>0.4$ [32]. Cytoscape (3.7.2) software was applied to visualize the PPI network in this study.

\section{Immunohistochemistry (IHC) experiment reagents and clinical samples}

A total of 204 clinical samples were collected from the Department of Respiratory Medicine, The Second Affiliated Hospital of Chongqing Medical University. They contain 102 LUAD tissues and 102 normal samples. Ethics approval of the Hospital Institutional Board and informed consent from the patients were obtained (Chongqing, China). Clinical tissue samples were made into paraffin sections in pathology department. Dewaxing of paraffin sections was performed in oven at $56^{\circ} \mathrm{C}$ for 2 hours. Antigen retrieval and blocking were applied by citrate buffer and $3 \% \mathrm{H}_{2} \mathrm{O}_{2}$. Then incubation of the primary antibody was applied on sections overnight at $4^{\circ} \mathrm{C}$ by anti-CHRDL1 (GTX117884, GeneTex, USA) and anti-CD30 (GTX01872, GeneTex, USA). On the second day, the sections were continually incubated at $37^{\circ} \mathrm{C}$ for 1 hour with HRP-conjugated secondary antibody (G1213, Servicebio, China). Moreover, staining counterstain of the sections were worked by DAB coloration kits (G1212, Servicebio, China) and hematoxylin (G1004, Servicebio, China). Dehydration of the sections was applied with a graded series of ethanol. Finally, ImagePro Plus software was used to quantify the IHC staining intensity of the sections by integrated optical density (IOD).

\section{Statistical analysis}

The statistical analysis and plots were performed using $\mathrm{R}$ (v.3.6.0). Receiver operating characteristic (ROC) analysis, Wilcoxon rank sum test and signed rank test were implemented in the expression of CHRDL1 in normal samples and tumor samples [33, 34]. KruskalWallis and Wilcoxon rank sum test were performed to assess relationships between clinicopathologic features and the specific expression of CHRDL1. The Pearson $\mathrm{X}^{2}$ test, $t$ test and logistic regression were applied to analyze the correlation between clinicopathologic variables and low/high CHRDL1 expression group. Survival curve based on Kaplan-Meier method were drawn to assess the prognostic value of CHRDL1 on overall survival (OS), disease-specific survival (DSS) and progression-free survival (PFS). Cox logistic regression models were constructed to identify independent variables by univariate and multivariate regression analysis [35]. And then, the rms (https://cran.r-project.org/web/package/rms /index.html) packages was applied to establish a nomogram with these independent variables. The concordance index (C-index) was calculated to evaluate the predictive ability of the model. A calibration curve was constructed to evaluate the prediction accuracy of the nomogram based on the prognostic model [36].

\section{RESULTS}

\section{Expression differences of CHRDL1 in tumor tissues and normal samples}

The expression of CHRDL1 was visualized in normal samples and LUAD samples based on GTEx and TCGA. Obviously, CHRDL1 expression of tumor tissues was significantly decreased compared with normal samples in LUAD (Figure1A, $P<0.001$ ). And the consistent results were found in paired tumor tissues and adjacent samples from TCGA (Figure 1B, $P<0.001)$. Moreover, CHRDL1 expression revealed promising discrimination power as the ROC curve showed that the AUC of CHRDL1 expression for identifying LUAD from normal tissues was 0.938 (CI=0.913-0.962, Figure 1C). Pan-cancer analysis showed CHRDL1 was also low expressed in most types of tumors (Figure 1D).

\section{CHRDL1 expression correlated with clinicopathologic features}

The clinicopathologic features of LUAD patients were downloaded from TCGA, including gender, race, TNM stage, pathologic stage, primary therapy outcome, smoking history, TP53 status and KARS status (Table 1). The results illustrated that CHRDL1 was significantly correlative with $\mathrm{T}$ stage $(P<0.001), \mathrm{N}$ stage $(P=0.008)$, pathologic stage $(P=0.004)$, tumor status $(P=0.023)$, TP53 status $(P<0.001)$, gender $(P=0.003)$ and age $(P=0.003)$. And there was no relation between CHRDL1 expression and other clinicopathologic features [37].

Then, 513 patients were separated into high and low CHRDL1 groups based on the median value of CHRDL1 expression. The results of the box plot showed that a lower level of CHRDL1 was significantly correlative with a higher $\mathrm{T}$ stage $(P<0.001), \mathrm{N}$ stage $(P=0.019)$ and pathologic stage $(P=0.007$, Figure $2 \mathrm{~A}-$ $2 \mathrm{C})$. The positive cancer status was correlated with lower CHRDL1 expression $(P=0.006$, Figure 2D). Moreover, poor treatment outcome $(P=0.03)$ and TP53 mutation $(P<0.001)$ were also significantly correlated with lower expression of CHRDL1 (Figure 2E, 2F). Finally, a higher level of CHRDL1 was significantly associated with female $(P<0.001)$ and the elderly (age $>65, P<0.001$, Figure 2G, 2H).

Coincidentally, logistic regression indicated that lower CHRDL1 expression levels were significantly 
associated with poor prognostic characteristics (Table 2 ), including LUAD patients with a larger tumor extent ( $\mathrm{QR}=0.45, P<0.001)$, higher level of regional lymph node invasion $(\mathrm{QR}=0.57, \quad P<0.003)$, advanced pathologic stage $(\mathrm{QR}=0.53, P<0.001)$, worse treatment effect $\quad(\mathrm{QR}=0.64, \quad P=0.047)$, poor cancer status $(\mathrm{QR}=0.63, P=0.018)$, and TP53 mutation $(\mathrm{QR}=0.49$, $P<0.001)$. These results implied that LUAD patients with low CHRDL1 were more related to poor clinicopathological features.

\section{The Kaplan-Meier and Cox regression analysis of} survival

As shown in Figure 3, LUAD patients with low CHRDL1 had a worse prognosis than that with high CHRDL1. The Kaplan-Meier analysis illustrated that low CHRDL1 was significantly correlative with a poor OS (HR $=0.60, P<0.001)$ and a shorter DSS $(\mathrm{HR}=0.66$, $P=0.031$, Figure $3 \mathrm{~A}, 3 \mathrm{~B}$ ). But there was no significant relevance between CHRDL1 expression and PFS
$(\mathrm{HR}=0.81, \quad P=0.14, \quad$ Figure $3 \mathrm{C})$. Univariate Cox regression analysis showed that several clinicopathologic characteristics were associated with poor OS (Table 3 ), including advanced $\mathrm{T}$ stage $(\mathrm{HR}=1.668, P=0.003), \mathrm{N}$ stage $\quad(\mathrm{HR}=2.606, \quad P<0.001), \quad \mathrm{M}$ stage $(\mathrm{HR}=2.111$, $P=0.007)$, poor pathologic stage $(\mathrm{HR}=2.975, P<0.001)$, worse treatment effect $(\mathrm{HR}=2.818, P<0.001)$, positive tumor status $(\mathrm{HR}=6.211, P<0.001)$ and low CHRDL1 $(\mathrm{HR}=0.598, P<0.001)$. Furthermore, multivariate analysis suggested that CHRDL1 was independently correlative with OS (Table 3), with a HR of $0.563(P=0.016)$, along with primary therapy outcome $(\mathrm{HR}=2.022, P=0.002)$ and tumor status $(\mathrm{HR}=5.956, P<0.001)$.

\section{A nomogram constructed by CHRDL1 and other independent clinical risk factors}

To supply an available quantitative approach of predicting the prognosis to clinical worker for LUAD patients, a nomogram was established by CHRDL1 and


Figure 1. Expression difference of CHRDL1 in normal samples and tumour samples. (A) Expression of CHRDL1 in normal samples from TCGA and GTEx and tumour sample of LUAD. (B) Expression levels of CHRDL1 in paired tumour and adjacent samples of LUAD. (C) ROC analysis of CHRDL1 expression showing promising discrimination power between tumor and non-tumor tissues in LUAD. (D) Expression levels of CHRDL1 in Pan-cancer. $\mathrm{ns}, \mathrm{P}$ ggreater than or equal to\}0.05; *, $\mathrm{P}<0.05 ; * *, \mathrm{P}<0.01 ; * * *, \mathrm{P}<0.001$. 
Table 1. Association between CHRDL1 expression and clinicopathologic features based on TCGA.

\begin{tabular}{|c|c|c|c|c|}
\hline \multirow{2}{*}{ Characters } & \multirow{2}{*}{ Level } & \multicolumn{2}{|c|}{ Expression of CHRDL1 } & \multirow{2}{*}{$P$ value } \\
\hline & & Low & High & \\
\hline \multirow[t]{2}{*}{$\mathrm{n}$} & & 257 & 256 & \\
\hline & $\mathrm{T} 1$ & $62(24.2 \%)$ & $106(41.7 \%)$ & $<0.001$ \\
\hline \multirow{4}{*}{ T stage } & $\mathrm{T} 2$ & $154(60.2 \%)$ & $122(48.0 \%)$ & \\
\hline & $\mathrm{T} 3$ & $27(10.5 \%)$ & $20(7.9 \%)$ & \\
\hline & $\mathrm{T} 4$ & $13(5.1 \%)$ & $6(2.4 \%)$ & \\
\hline & No & $153(59.8 \%)$ & $177(72.2 \%)$ & 0.008 \\
\hline \multirow{3}{*}{$\mathrm{N}$ stage } & N1 & $60(23.4 \%)$ & $35(14.3 \%)$ & \\
\hline & $\mathrm{N} 2$ & $41(16.0 \%)$ & $33(13.5 \%)$ & \\
\hline & N3 & $2(0.8 \%)$ & $0(0.0 \%)$ & \\
\hline \multirow{3}{*}{ M stage } & M0 & $176(93.1 \%)$ & $168(93.3 \%)$ & 1.000 \\
\hline & M1 & $13(6.9 \%)$ & $12(6.7 \%)$ & \\
\hline & Stage I & $118(46.5 \%)$ & $156(62.2 \%)$ & 0.004 \\
\hline \multirow{4}{*}{ Pathologic stage } & Stage II & $73(28.7 \%)$ & $48(19.1 \%)$ & \\
\hline & Stage III & $50(19.7 \%)$ & $34(13.5 \%)$ & \\
\hline & Stage IV & $13(5.1 \%)$ & $13(5.2 \%)$ & \\
\hline & $\mathrm{CR}$ & $147(69.7 \%)$ & $168(78.1 \%)$ & 0.127 \\
\hline \multirow{3}{*}{ Primary therapy outcome } & $\mathrm{PD}$ & $39(18.5 \%)$ & $29(13.5 \%)$ & \\
\hline & PR & $2(0.9 \%)$ & $4(1.9 \%)$ & \\
\hline & SD & $23(10.9 \%)$ & $14(6.5 \%)$ & \\
\hline \multirow{3}{*}{ Gender } & Female & $121(47.1 \%)$ & $155(60.5 \%)$ & 0.003 \\
\hline & Male & $136(52.9 \%)$ & $101(39.5 \%)$ & \\
\hline & Asian & $5(2.3 \%)$ & $2(0.9 \%)$ & 0.435 \\
\hline \multirow[t]{2}{*}{ Race } & Black or African American & $27(12.3 \%)$ & $25(11.0 \%)$ & \\
\hline & White & $187(85.4 \%)$ & $200(88.1 \%)$ & \\
\hline \multirow{2}{*}{ Smoker } & No & $30(12.0 \%)$ & $44(17.7 \%)$ & 0.090 \\
\hline & Yes & $221(88.0 \%)$ & $204(82.3 \%)$ & \\
\hline \multirow{2}{*}{ Tumor status } & Tumor free & $128(57.4 \%)$ & $160(68.1 \%)$ & 0.023 \\
\hline & With tumor & $95(42.6 \%)$ & $75(31.9 \%)$ & \\
\hline \multirow{2}{*}{ TP53 status } & Mut & $144(56.2 \%)$ & $97(38.5 \%)$ & $<0.001$ \\
\hline & WT & $112(43.8 \%)$ & $155(61.5 \%)$ & \\
\hline \multirow{2}{*}{ KRAS status } & Mut & $74(28.9 \%)$ & $65(25.8 \%)$ & 0.492 \\
\hline & WT & $182(71.1 \%)$ & $187(74.2 \%)$ & \\
\hline
\end{tabular}

CR, complete response; PD, progressive disease; PR, partial response; SD, stable disease; Mut, mutation type; WT, wild type.

other independent clinical risk factors (primary therapy outcome and tumor status). Obviously, the nomogram showed that CHRDL1 possessed a certain predictive efficacy for the prognosis of patients with LUAD (Figure 4A). And its C-index was 0.752 ( $\mathrm{CI}=0.727$ 0.776), which indicated that the predictive ability of the nomogram has medium accuracy. Besides, the calibration curve of the nomogram was found very close to the ideal $45^{\circ} \mathrm{C}$ curve, indicating favorable consistency between the prediction and the observation (Figure 4B). Thus, these results demonstrated that the nomogram was an effective measurement for predicting survival period in LUAD patients.

\section{Identification of DEGs}

To better elucidate the underlying mechanisms of CHRDL1 expression in LUAD, a total of 501 DEGs were screened after the analyses of TCGA RNAseq data. DEGs expressions were illustrated by Volcano plot (Figure 5A). And PPI of CHRDL1 related co-expressed genes were established (Supplementary Figure 1). 
Functional enrichment analysis of DEGs

To further elucidate the role of CHRDL1 in LUAD, GO and KEGG analysis was performed by ClusterProfiler package (Table 4). In the biological process category [38], 225 enriched GO terms were discovered. Among them, they mainly participated in humoral immune response (GO:0006959), positive regulation of secretion (GO:0051047), positive regulation of secretion by cell
(GO:1903532), muscle system process (GO:0003012), muscle system process modulation of chemical synaptic (GO:0050804) and regulation of trans-synaptic signaling (GO:0099177) (Figure 5B). Categorization by "cellular component" revealed 28 enriched terms, they were mainly enriched in collagen-containing extracellular matrix (GO:0062023), presynapse (GO:0098793), neuronal cell body (GO:0043025), apical part of cell (GO:0045177),
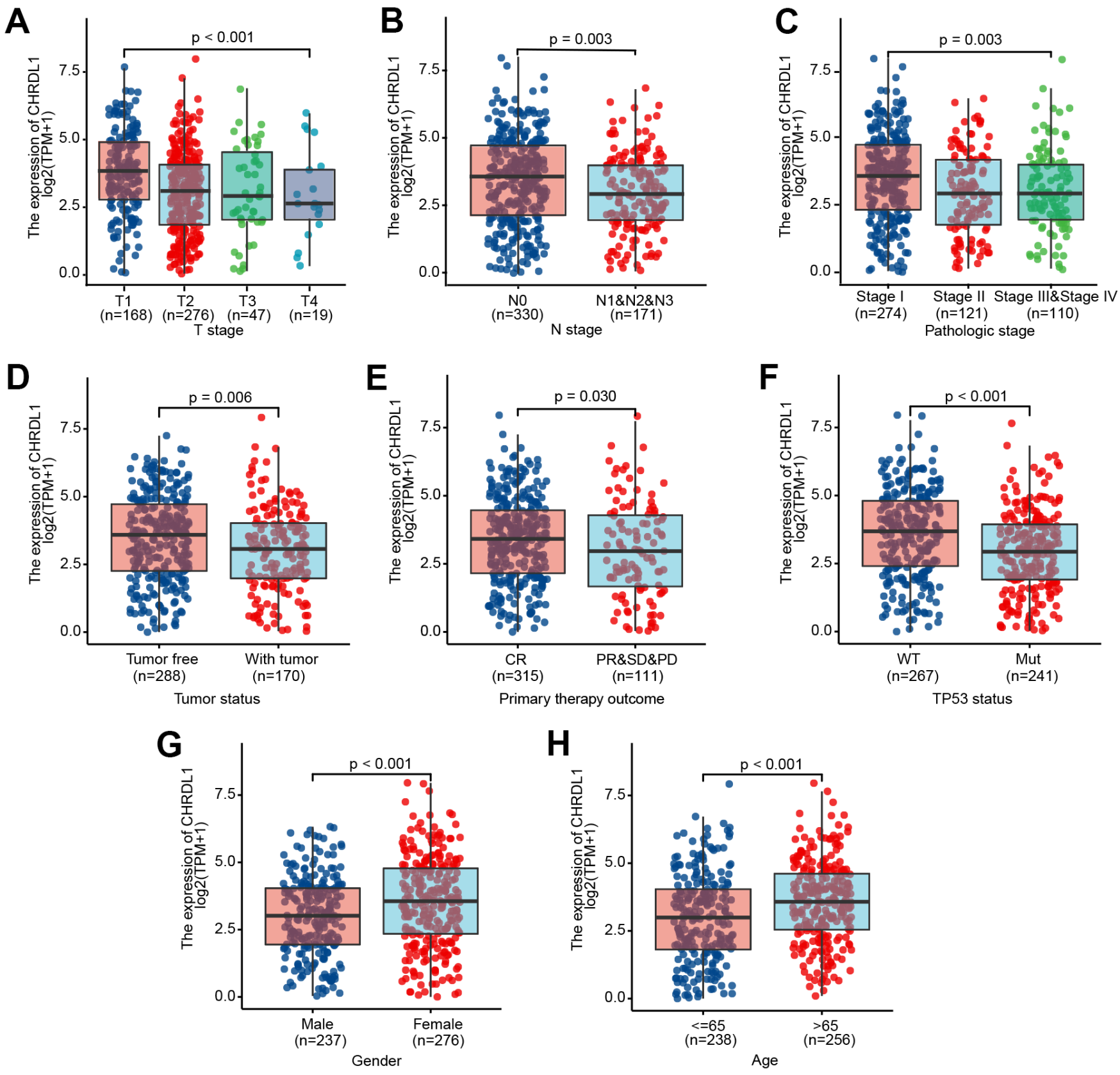

Figure 2. Association between CHRDL1 expression and clinicopathologic characteristics, including $(\mathbf{A}-\mathbf{H}): \mathrm{T}$ stage $(\mathrm{P}<0.001), \mathrm{N}$ stage $(P=0.003)$, Pathologic stage $(P=0.003)$, Tumor status $(P=0.006)$, Primary therapy outcome $(P=0.030)$, TP53 status $(P<0.001)$, Gender $(P<0.001)$ and Age $(P<0.001)$ in patients with LUAD in a TCGA cohort. 
Table 2. CHRDL1 expression associated with clinical pathological characteristics (logistic regression).

\begin{tabular}{lccc}
\hline Characteristics & Total number & OR $(\mathbf{9 5 \%}$ CI) & $\boldsymbol{P}$ value \\
\hline T stage (T2\&T3\&T4 vs. T1) & 510 & $0.45(0.30-0.65)$ & $<0.001$ \\
N stage (N1\&N2\&N3 vs. N0) & 501 & $0.57(0.39-0.83)$ & 0.003 \\
M stage (M1 vs. M0) & 369 & $0.97(0.42-2.19)$ & 0.936 \\
Pathologic stage (Stage II\&StageIII\&Stage IV vs. Stage I) & 505 & $0.53(0.37-0.75)$ & $<0.001$ \\
Primary therapy outcome (PD\&SD\&PR vs. CR) & 426 & $0.64(0.41-0.99)$ & 0.047 \\
Tumor status (With tumor vs. Tumor free) & 458 & $0.63(0.43-0.92)$ & 0.018 \\
TP53 status (Mut vs. WT) & 508 & $0.49(0.34-0.69)$ & $<0.001$ \\
KRAS status (Mut vs. WT) & 508 & $0.85(0.58-1.26)$ & 0.432 \\
\hline
\end{tabular}

$\mathrm{OR}$, odds ratio; $\mathrm{Cl}$, confidence interval; $\mathrm{CR}$, complete response; $\mathrm{PD}$, progressive disease; $\mathrm{PR}$, partial response; $\mathrm{SD}$, stable disease; Mut, mutation type; WT, wild type.

synaptic membrane (GO:0097060) and apical plasma membrane (GO:0016324) (Figure 5C). In addition, the "molecular function" category disclosed 30 significant enrichment in terms and mainly associated with receptor ligand activity (GO:0048018), sulfur compound binding (GO:1901681), organic acid binding (GO:00431 77), heparin binding (GO:0008201), carboxylic acid binding (GO:0031406) and hormone activity (GO:000517 9) (Figure 5D). KEGG analysis revealed changes in genes sets related to neuroactive ligand-receptor interaction (hs a04080), complement and coagulation cascades (hsa046 10), steroid hormone biosynthesis (hsa00140), retinol metabolism (hsa00830) and metabolism of xenobiotics by cytochrome P450 (hsa00980) [39, 40] (Figure 5E). These results may confirm the importance of CHRDL1 in body homeostasis and neural signal transduction.

\section{Signaling pathways related CHRDL1 based on GSEA}

Signaling pathways related CHRDL1 were identified by GSEA (Table 5). Three pathways showed significantly differential enrichments in CHRDL1 high expression phenotype (Figure 6A-6C), including immunoregulatory interactions between a lymphoid and a non-lymphoid cell, antigen activates $B$ cell receptor (BCR) leading to generation of second messengers and intestinal immune network for IgA production. And cell cycle checkpoints, translation and G2M checkpoints suggested significantly differential enrichment in low CHRDL1 group (Figure 6D-6F). These results suggested the link between CHRDL1 and immune regulation and cell cycle in LUAD.
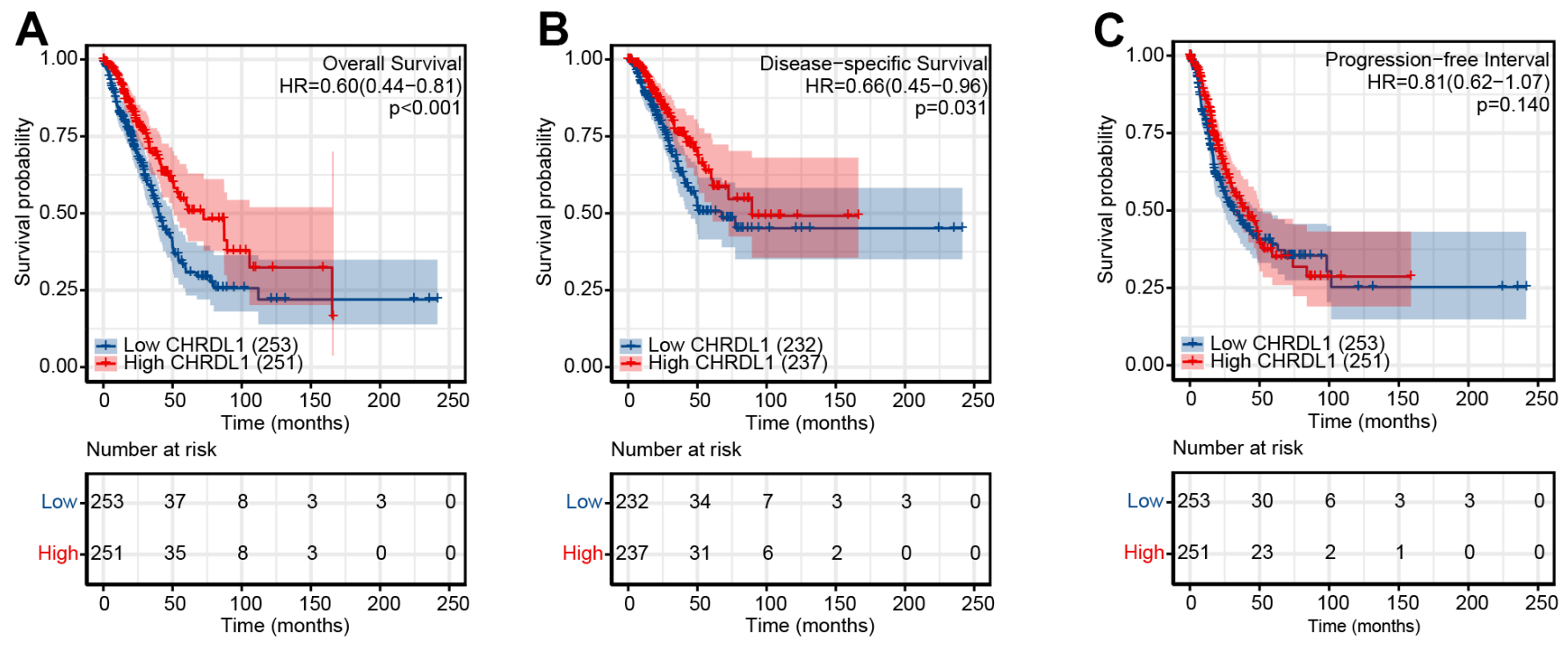

Figure 3. Impact of CHRDL1 expression on OS (A), DSS (B) and DFS (C) in patients with LUAD in a TCGA cohort. The bottom half of the picture showed that the risk table records the number of people who were still following at each point in time. 
Table 3. Associations between overall survival clinicopathological characteristics in TCGA patients with Cox regression.

\begin{tabular}{|c|c|c|c|c|c|}
\hline \multirow{2}{*}{ Characteristics } & \multirow{2}{*}{$\mathbf{N}$} & \multicolumn{2}{|c|}{ Univariate analysis } & \multicolumn{2}{|c|}{ Multivariate analysis } \\
\hline & & HR $(95 \%$ CI $)$ & $P$ value & HR $(95 \%$ CI $)$ & $P$ value \\
\hline Gender (Female vs. Male) & 504 & $\begin{array}{c}0.943 \\
(0.705-1.262)\end{array}$ & 0.694 & & \\
\hline Age $(>65$ vs. $<=65)$ & 494 & $\begin{array}{c}1.228 \\
(0.915-1.649)\end{array}$ & 0.171 & & \\
\hline Smoker (Yes vs. No) & 490 & $\begin{array}{c}0.887 \\
(0.587-1.339)\end{array}$ & 0.568 & & \\
\hline T stage (T2\&T3\&T4 vs. T1) & 501 & $\begin{array}{c}1.668 \\
(1.184-2.349)\end{array}$ & 0.003 & $\begin{array}{c}1.346 \\
(0.789-2.296)\end{array}$ & 0.275 \\
\hline N stage (N1\&N2\&N3 vs. N0) & 492 & $\begin{array}{c}2.606 \\
(1.939-3.503)\end{array}$ & $<0.001$ & $\begin{array}{c}1.542 \\
(0.754-3.152)\end{array}$ & 0.235 \\
\hline M stage (M1 vs. M0) & 360 & $\begin{array}{c}2.111 \\
(1.232-3.616)\end{array}$ & 0.007 & $\begin{array}{c}0.864 \\
(0.363-2.058)\end{array}$ & 0.741 \\
\hline $\begin{array}{l}\text { Pathologic stage (Stage II\&Stage } \\
\text { III\&Stage IV vs. Stage I) }\end{array}$ & 496 & $\begin{array}{c}2.975 \\
(2.188-4.045)\end{array}$ & $<0.001$ & $\begin{array}{c}0.936 \\
(0.425-2.059)\end{array}$ & 0.869 \\
\hline $\begin{array}{l}\text { Primary therapy outcome } \\
\text { (PR\&SD\&PD vs. CR) }\end{array}$ & 419 & $\begin{array}{c}2.818 \\
(2.004-3.963)\end{array}$ & $<0.001$ & $\begin{array}{c}2.022 \\
(1.284-3.184)\end{array}$ & 0.002 \\
\hline $\begin{array}{l}\text { Tumor status (With tumor vs. Tumor } \\
\text { free) }\end{array}$ & 450 & $\begin{array}{c}6.211 \\
(4.258-9.059)\end{array}$ & $<0.001$ & $\begin{array}{c}5.956 \\
(3.542-10.016)\end{array}$ & $<0.001$ \\
\hline TP53 status (Mut vs. WT) & 499 & $\begin{array}{c}1.254 \\
(0.936-1.680)\end{array}$ & 0.130 & & \\
\hline KRAS status (Mut vs. WT) & 499 & $\begin{array}{c}1.087 \\
(0.779-1.517)\end{array}$ & 0.623 & & \\
\hline CHRDL1 (High vs. Low) & 504 & $\begin{array}{c}0.598 \\
(0.444-0.807) \\
\end{array}$ & $<0.001$ & $\begin{array}{c}0.563 \\
(0.353-0.899) \\
\end{array}$ & 0.016 \\
\hline
\end{tabular}

$\mathrm{HR}$, Hazard Ratio; $\mathrm{Cl}$, confidence interval; $\mathrm{CR}$, complete response; PD, progressive disease; PR, partial response; SD, stable disease; Mut, mutation type; WT, wild type CR, complete response; PD, progressive disease; PR, partial response; SD, stable disease.
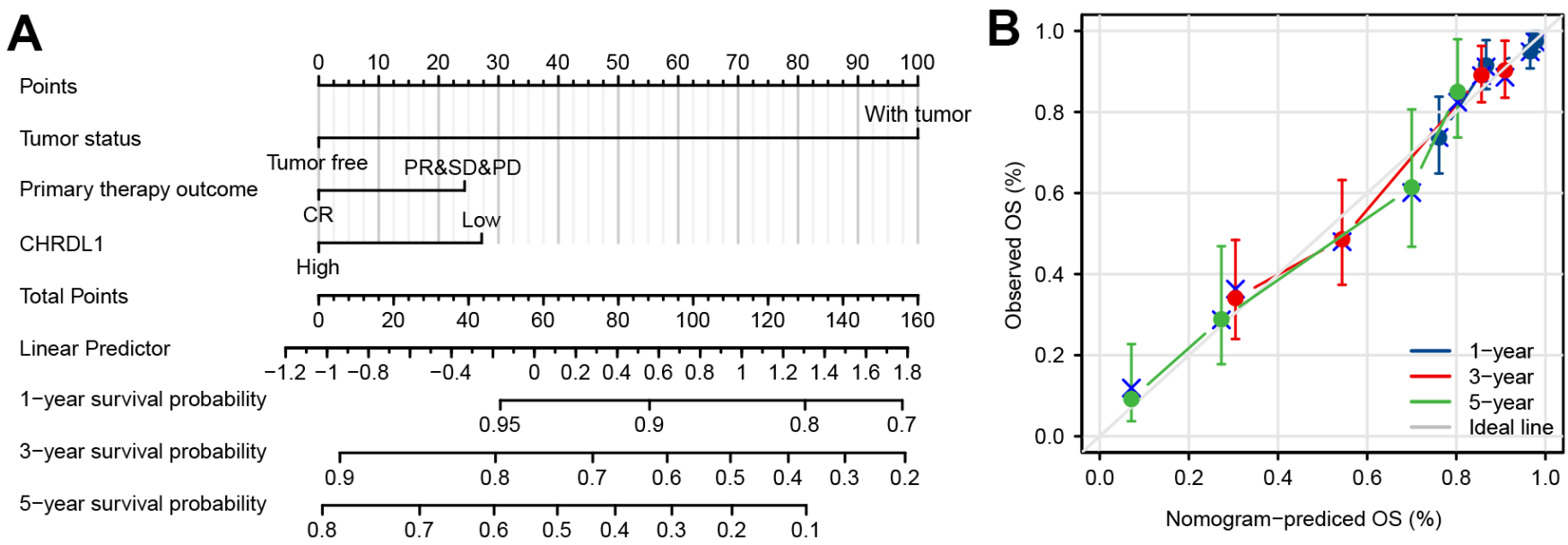

Figure 4. Construction and validation of a nomogram based on the CHRDL1. (A) nomogram to predict survival probability at 1, 3, and 5 years for LUAD patients. The C-index for the nomogram was 0.752 ( $\mathrm{Cl}=0.727-0.776)$ with 1000 bootstrap replicates. (B) Calibration curve with the Hosmer-Lemeshow test of the nomogram in the TCGA-LUAD cohort. 
The correlation between CHRDL1 and immune infiltration

Immune infiltration analysis showed that CHRDL1 was significantly associated with 7 kinds of immune cells
(Figure 7A and Supplementary Figure 2), including Mast cells $(\mathrm{R}=0.583, P<0.001)$, iDCs $(\mathrm{R}=0.493, P<0.001)$, Eosinophils $\quad(\mathrm{R}=0.485, \quad P<0.001), \quad \mathrm{DCs} \quad(\mathrm{R}=0.434$, $P<0.001)$ Macrophages $(\mathrm{R}=0.421, \quad P<0.001), \quad \mathrm{Tfh}$ $(\mathrm{R}=0.421, P<0.001)$ and $\mathrm{Th} 2$ cells $(\mathrm{R}=-0.402, P<0.001)$.
A
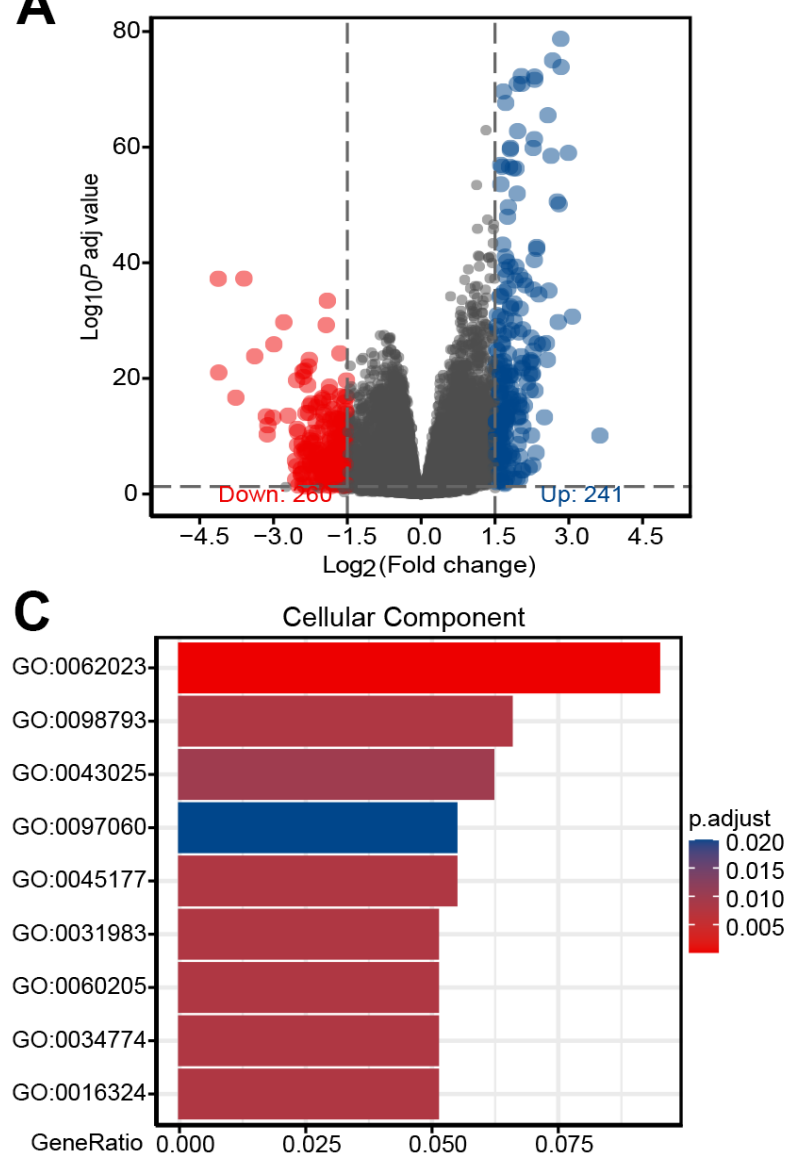
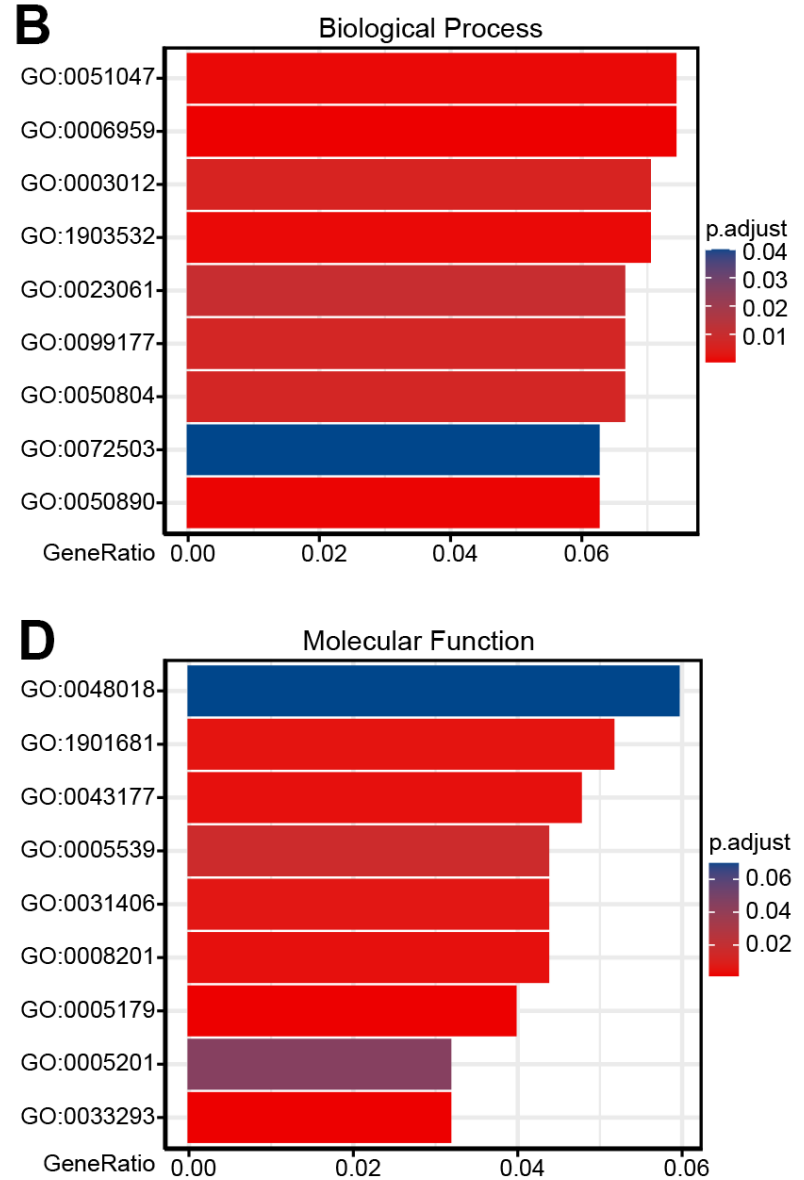

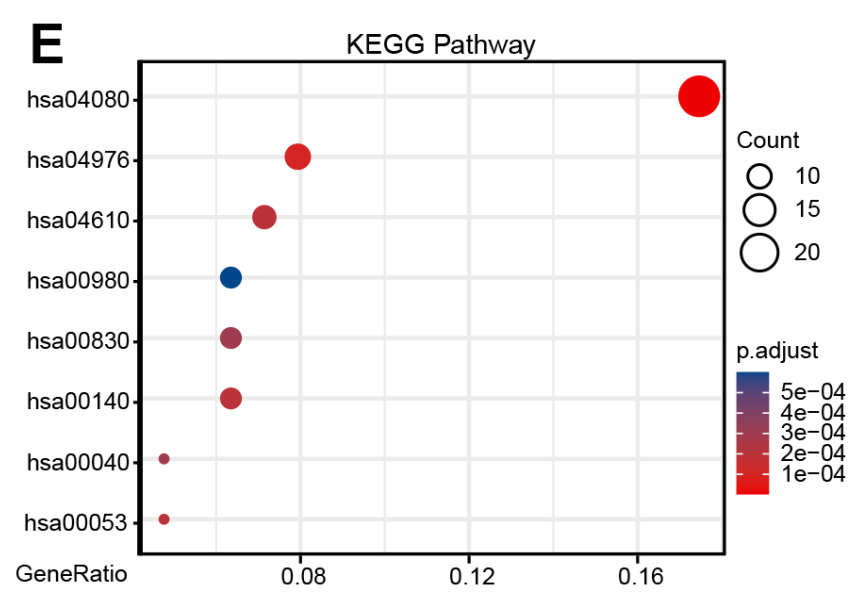

Figure 5. Identification of DEGs and functional enrichment analysis of DEGs. (A) Volcano plot of differential gene profiles between CHRDL1-high and -low groups. A total of 501 DEGs (241 upregulated and 260 downregulated) were identified. (B) Enriched GO terms in the "Biological Process" category. (C) Enriched GO terms in the "Cellular Component" category. (D) Enriched GO terms in the "Molecular Function" category. (E) Enriched GO terms in the "KEGG Pathway" category. The x-axis represents the proportion of DEGs, and the $y$-axis represents different categories. The colors indicate adjusted P-value, and the column lengths and circle sizes represent the enriched number of DEGs. 
Table 4. Functional enrichment analysis of DEGs.

\begin{tabular}{|c|c|c|c|c|}
\hline ONTOLOGY & ID & Description & $P$.adjust & Count \\
\hline $\mathrm{BP}$ & GO:0006959 & humoral immune response & $1.412400 \mathrm{E}-04$ & 19 \\
\hline $\mathrm{BP}$ & GO:0051047 & positive regulation of secretion & $1.009938 \mathrm{E}-03$ & 19 \\
\hline BP & GO:1903532 & positive regulation of secretion by cell & $1.207653 \mathrm{E}-03$ & 18 \\
\hline BP & GO:0003012 & muscle system process & $5.775649 \mathrm{E}-03$ & 18 \\
\hline BP & GO:0050804 & modulation of chemical synaptic transmission & $6.625203 \mathrm{E}-03$ & 17 \\
\hline BP & GO:0099177 & regulation of trans-synaptic signaling & $6.683871 \mathrm{E}-03$ & 17 \\
\hline BP & GO:0023061 & signal release & $1.025742 \mathrm{E}-02$ & 17 \\
\hline $\mathrm{BP}$ & GO:0050890 & cognition & $5.351450 \mathrm{E}-04$ & 16 \\
\hline BP & GO:0072503 & cellular divalent inorganic cation homeostasis & 3.519247E-02 & 16 \\
\hline $\mathrm{CC}$ & GO:0062023 & collagen-containing extracellular matrix & $3.410000 \mathrm{E}-08$ & 26 \\
\hline $\mathrm{CC}$ & GO:0098793 & presynapse & $7.581631 \mathrm{E}-03$ & 18 \\
\hline $\mathrm{CC}$ & GO:0043025 & neuronal cell body & $1.252760 \mathrm{E}-02$ & 17 \\
\hline $\mathrm{CC}$ & GO:0045177 & apical part of cell & 7.669858E-03 & 15 \\
\hline $\mathrm{CC}$ & GO:0097060 & synaptic membrane & $1.878734 \mathrm{E}-02$ & 15 \\
\hline $\mathrm{CC}$ & GO:0016324 & apical plasma membrane & $7.581631 \mathrm{E}-03$ & 14 \\
\hline $\mathrm{CC}$ & GO:0034774 & secretory granule lumen & $7.581631 \mathrm{E}-03$ & 14 \\
\hline $\mathrm{CC}$ & GO:0060205 & cytoplasmic vesicle lumen & $7.669858 \mathrm{E}-03$ & 14 \\
\hline $\mathrm{CC}$ & GO:0031983 & vesicle lumen & $7.669858 \mathrm{E}-03$ & 14 \\
\hline MF & GO:0048018 & receptor ligand activity & $6.958732 \mathrm{E}-02$ & 15 \\
\hline MF & GO:1901681 & sulfur compound binding & $4.876470 \mathrm{E}-03$ & 13 \\
\hline MF & GO:0043177 & organic acid binding & $3.588468 \mathrm{E}-03$ & 12 \\
\hline MF & GO:0008201 & heparin binding & $3.584050 \mathrm{E}-03$ & 11 \\
\hline MF & GO:0031406 & carboxylic acid binding & $6.395279 \mathrm{E}-03$ & 11 \\
\hline MF & GO:0005539 & glycosaminoglycan binding & $1.615000 \mathrm{E}-02$ & 11 \\
\hline MF & GO:0005179 & hormone activity & $1.492445 \mathrm{E}-03$ & 10 \\
\hline MF & GO:0033293 & monocarboxylic acid binding & $1.443176 \mathrm{E}-03$ & 8 \\
\hline \multirow[t]{2}{*}{ MF } & GO:0005201 & extracellular matrix structural constituent & $4.511226 \mathrm{E}-02$ & 8 \\
\hline & ID & Description & P.adjust & Count \\
\hline KEGG & hsa04080 & Neuroactive ligand-receptor interaction & $2.590000 \mathrm{E}-06$ & 22 \\
\hline KEGG & hsa04610 & Complement and coagulation cascades & $3.407000 \mathrm{E}-04$ & 9 \\
\hline KEGG & hsa00140 & Steroid hormone biosynthesis & $2.986370 \mathrm{E}-04$ & 8 \\
\hline KEGG & hsa00830 & Retinol metabolism & 3.666170E-04 & 8 \\
\hline KEGG & hsa00980 & Metabolism of xenobiotics by cytochrome P450 & $7.403330 \mathrm{E}-04$ & 8 \\
\hline KEGG & hsa05204 & Chemical carcinogenesis & $9.972090 \mathrm{E}-04$ & 8 \\
\hline KEGG & hsa00053 & Ascorbate and aldarate metabolism & $2.986370 \mathrm{E}-04$ & 6 \\
\hline KEGG & hsa00040 & Pentose and glucuronate interconversions & 4.249400E-04 & 6 \\
\hline KEGG & hsa00860 & Porphyrin and chlorophyll metabolism & $9.972090 \mathrm{E}-04$ & 6 \\
\hline
\end{tabular}

$\mathrm{BP}$, biological process; CC, cellular component; MF, molecular function.

Then, the differences of infiltration level for these immune cells between high and low CHRDL1 groups were analyzed $(P<0.001$, Figure $7 \mathrm{~B}-7 \mathrm{H})$.

\section{Experimental verification of the expression and prognosis value of CHRDL1 by IHC}

Immunohistochemistry (IHC) was applied to 102 LUAD tissues and 102 normal samples (Figure 8A). The results indicated that CHRDL1 expression was significantly elevated in LUAD tissues comparing to normal samples. To verify the negative relation between CHRDL1 and Th2 cells, CD30 was detected in LUAD tissues, which can reveal the activity of Th2 cells. Our results suggested that $\mathrm{CD} 30$ was significantly upregulated in normal samples, which has the opposite result to expression of CHRDL1 in normal samples. Moreover, CHRDL1 was quantified by integrated optical density (IOD) in 204 samples. Combined with the clinical information, the results verified that a lower 
Table 5. CHRDL1 related signaling pathways based on GSEA.

\begin{tabular}{|c|c|c|c|c|c|}
\hline ID & Set size & $\begin{array}{l}\text { Enrichment } \\
\text { score }\end{array}$ & NES & $P$.adjust & FDR \\
\hline REACTOME Immunoregulatory interactions between a lymphoid and a non lymphoid cell & 179 & 0.666 & 2.564 & 0.02 & 0.014 \\
\hline $\begin{array}{l}\text { REACTOME Antigen activates B cell receptor (BCR) leading to generation of second } \\
\text { messengers }\end{array}$ & 83 & 0.704 & 2.438 & 0.02 & 0.014 \\
\hline KEGG Intestinal immune network for IgA production & 45 & 0.787 & 2.424 & 0.02 & 0.014 \\
\hline REACTOME G2M checkpoints & 145 & -0.666 & -2.402 & 0.02 & 0.014 \\
\hline REACTOME Translation & 287 & -0.614 & -2.412 & 0.02 & 0.014 \\
\hline REACTOME Cell cycle checkpoints & 263 & -0.638 & -2.471 & 0.02 & 0.014 \\
\hline
\end{tabular}

NES, normalized enrichment score; FDR, false discovery rate.

level of CHRDL1 was significantly correlative with a higher $\mathrm{T}$ stage $(P<0.001)$ and $\mathrm{N}$ stage $(P<0.001$, Figure $8 \mathrm{~B}, 8 \mathrm{C}$ ). ROC curve verified that CHRDL1 had a good ability to distinguish LUAD tissue from normal tissue (AUC $=0.991$,Figure 8D). Results of the survival curve illustrated that the patients with low CHRDL1 had poor OS $(P<0.034$, Figure $8 \mathrm{E})$. These results confirmed the prognostic value including the correlation between CHRDL1 and patients TNM stage and survival time.

\section{DISCUSSION}

CHRDL1 (Chordin-like1) belongs to the Chordin family and is located on the $X$ chromosome $[13,41]$. Its function is mainly as a specific inhibitor of bone morphogenetic proteins (BMPs), especially bone morphogenetic protein4 (BMP4) [18, 42-44]. The abnormal expression of BMP4 has been confirmed in various cancers, including NSCLC [45, 46]. Interestingly, the role of BMP4 in LUAD and LUSC is
A REACTOME_IMMUNOREGULATORY

A INTERACTIONS_BETWEEN_A_LYMPHOID AND_A_NON_LYMPHOID_CELL

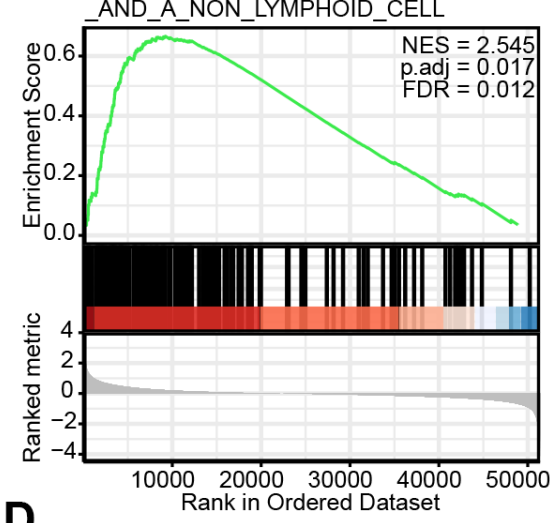

REACTOME_CELL CYCLE_CHECKPOINTS

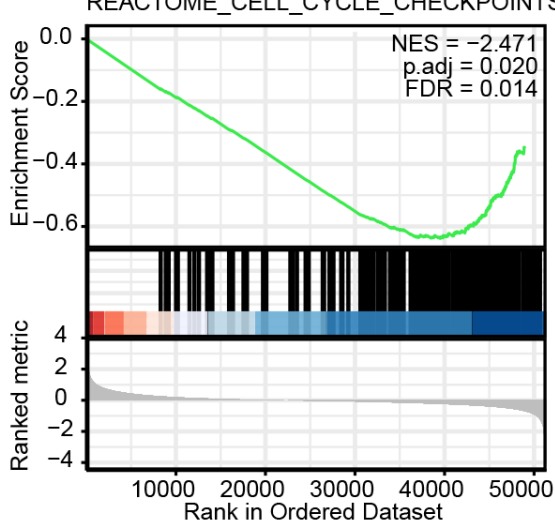

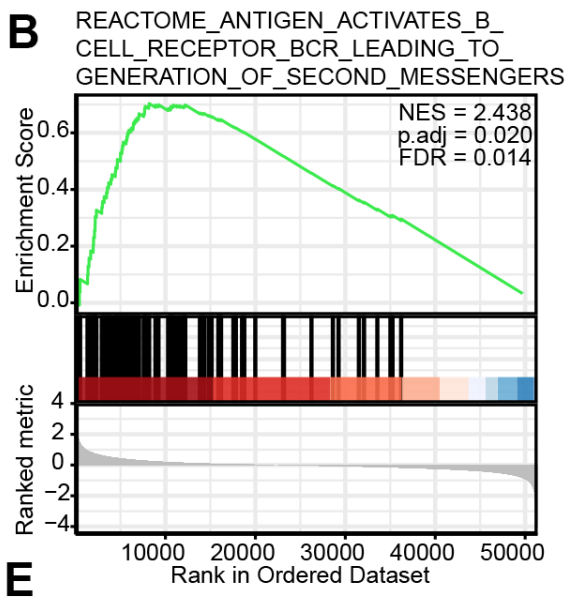

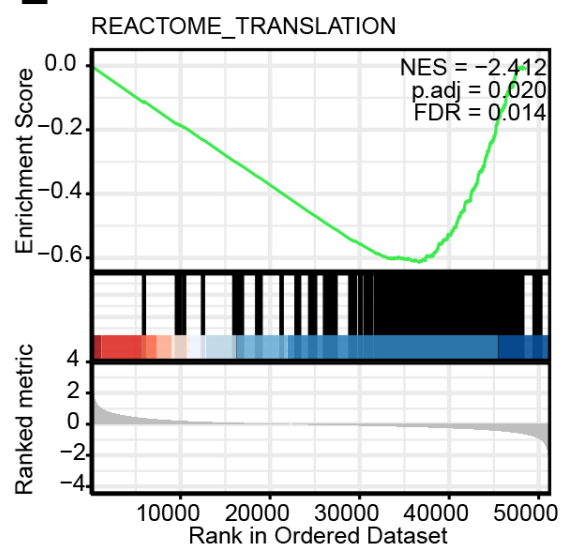

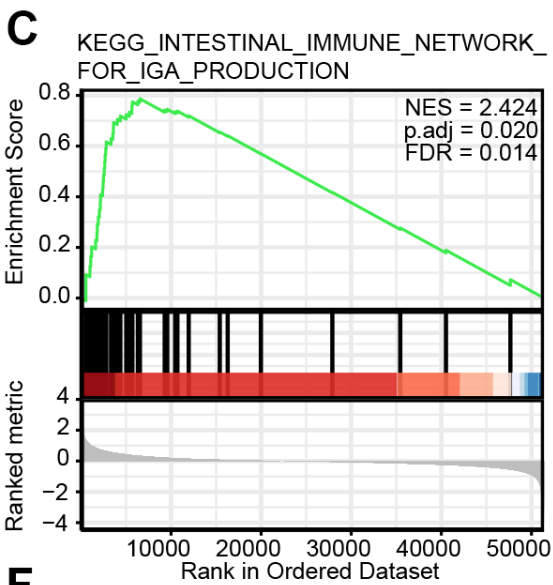

$\mathbf{F}$

REACTOME_G2_M_CHECKPOINTS

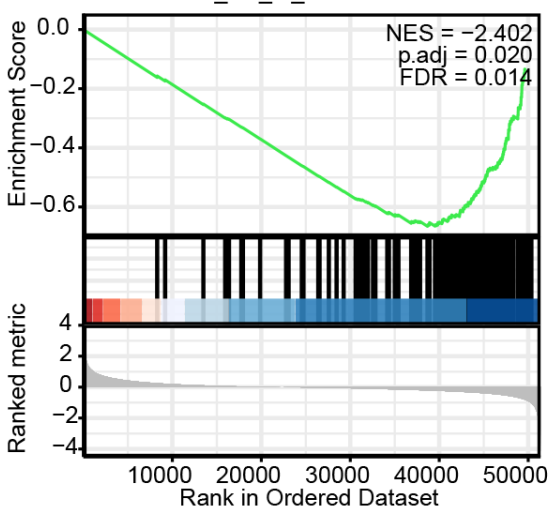

Figure 6. Enrichment plots from the gene set enrichment analysis (GSEA). (A-F) Several biological processes and pathways were differentially enriched in CHRDL1-related LUAD. NES, normalized ES; p.adj, adjusted P-value; FDR, false discovery rate. 
completely different. BMP4 could serve as a tumor suppressor in LUSC and inhibited the growth of LUSC cells [45]. In LUAD, BMP4 knockout could impede migration and invasion of LUAD cells [46]. However, CHRDL1, as a secretory antagonist of BMP4, is known little about its role in LUAD.

Recently, with the update of second-generation sequencing technology and establishment of public databases for sharing clinical data, more and more bioinformatics studies have achieved satisfactory results in the identification of key genes [47, 48]. In our study, RNA-sequencing profiles from TCGA were used to investigate the expression and prognosis value of CHRDL1 in LUAD. We found that CHRDL1 was significantly decreased in the majority of cancers. At present, the research of CHRDL1 in tumor is very scarce. In malignant melanoma, CHRDL1 was
A

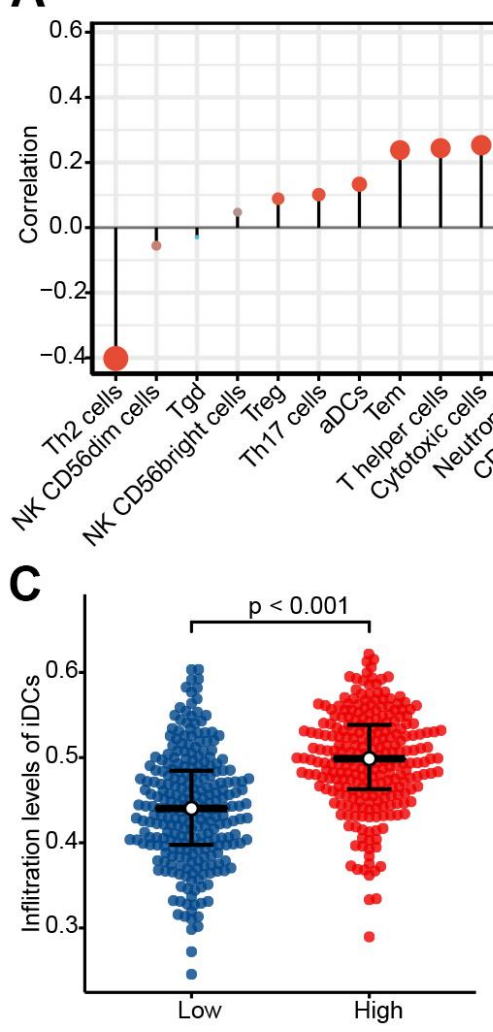

$\mathbf{F}$

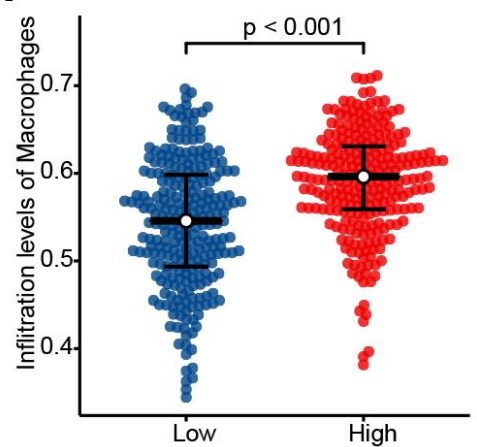

\section{D}

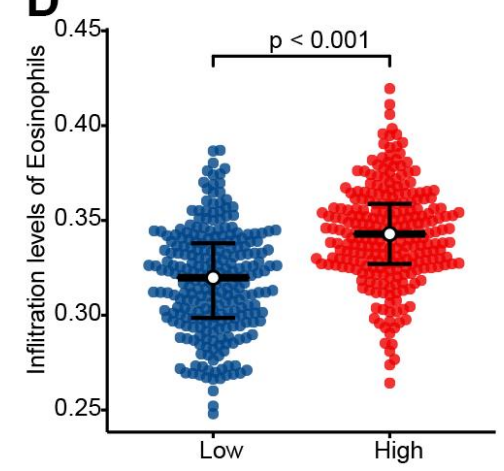

G

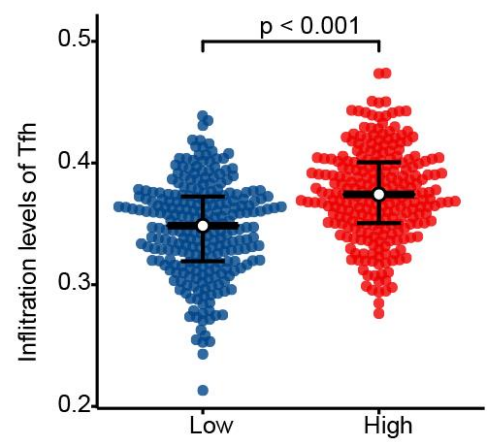

B

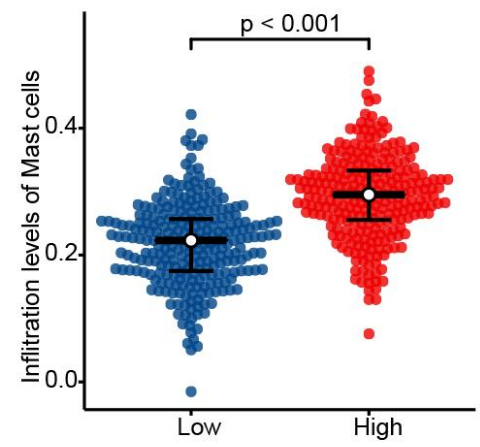

E

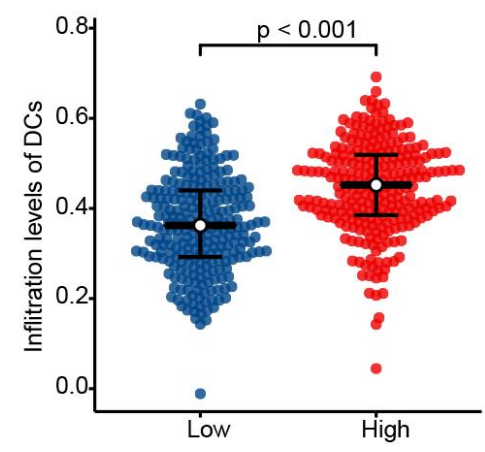

H

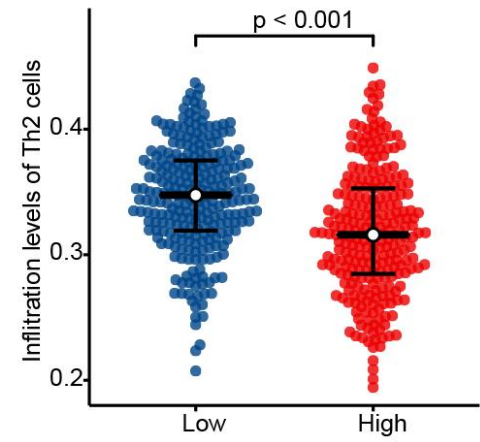

Figure 7. The expression level of CHRDL1 was associated with the immune infiltration in the tumour microenvironment. (A) Correlation between the relative abundances of 24 immune cells and CHRDL1 expression level. The size of the dots shows the absolute value of Spearman $r$. The colors represent the P-value. (B-H) The difference of immune cells infiltration level between CHRDL1 high and low expression groups was analyzed by Wilcoxon rank sum test. 

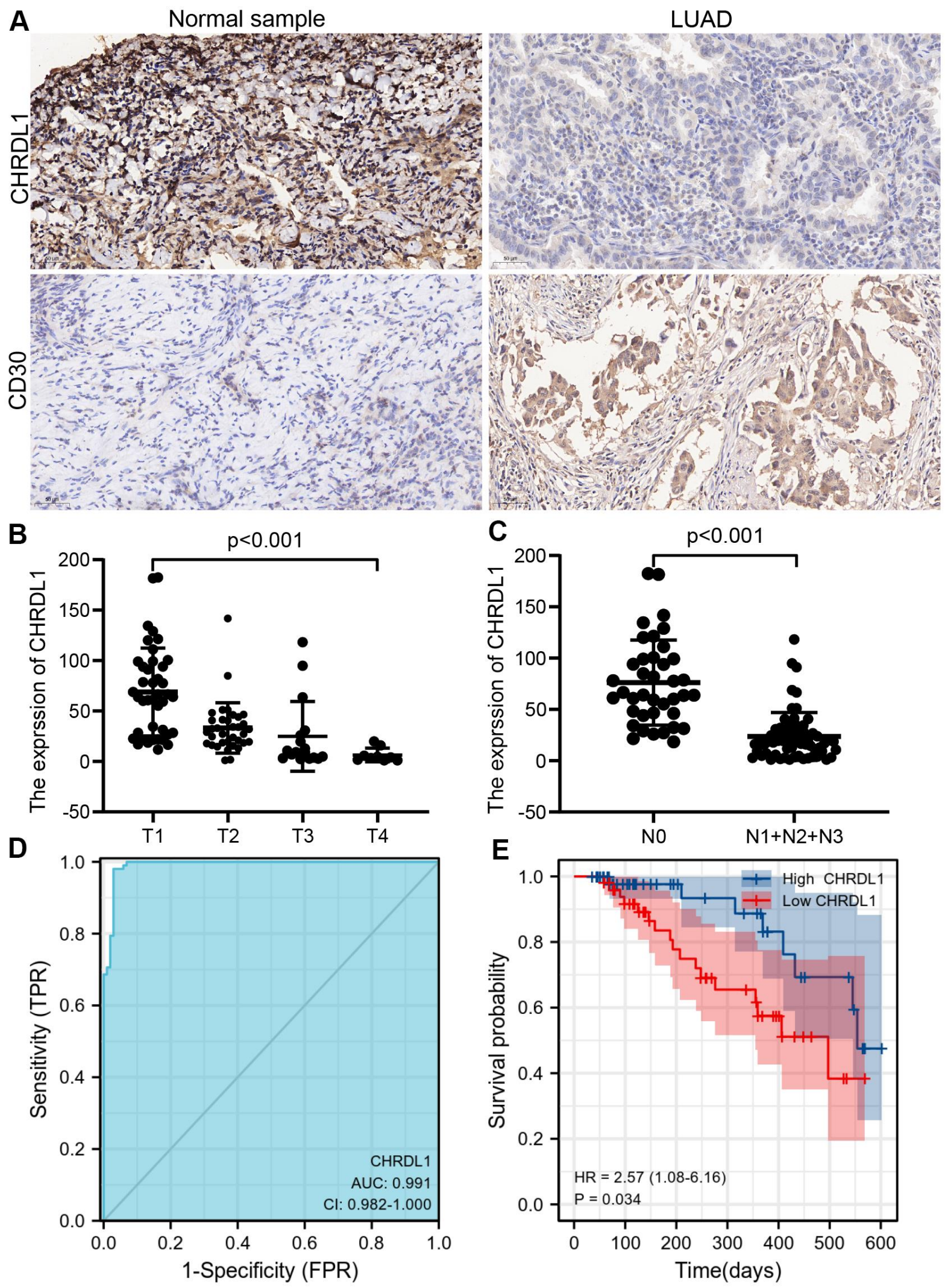

Figure 8. The experimental validation of CHRDL1 by IHC. (A) IHC staining of CHRDL1 and CD30 in normal sample and LUAD tissues. (B, C) Validation of association between CHRDL1 expression and TNM stage by IHC. (D) Validation of CHRDL1 expression showing discrimination power between normal samples and LUAD tissues by IHC. (E) Validation of the impact of CHRDL1 expression on overall survival in LUAD patients. 
identified as a tumour-suppressor gene and was significantly down-regulated in melanoma cell lines [16]. Abnormally elevated CHRDL1 was also found in $\mathrm{T}$ cell acute lymphoblastic leukemia [17]. Besides, down-regulation of CHRDL1 was observed in breast and gastric cancer [18, 19]. All the findings about the expression of CHRDL1 were consistent with our results in pan-cancer, and this also proved the reliability and authenticity of our study. Absolutely, the downregulated expression of CHRDL1 in LUAD also was verified according to our experimental validation by IHC.

Besides, it seems that the clinical significance of CHRDL1 is very impressive in our clinical correlation analysis. Our study suggested that low CHRDL1 in LUAD was significantly related to advanced clinicopathological features (high $\mathrm{T}$ and $\mathrm{N}$ stage, positive tumor status, poor treatment effect and TP53 mutation). TNM stage has been used to assess the severity of tumor extent, lymph node invasion and distant metastasis since 1966 [49]. In our study, CHRDL1 is only related to $\mathrm{T}$ and $\mathrm{N}$ stage, not to $\mathrm{M}$ stage. This maybe indicate that CHRDL1 is mainly involved in the regulation of tumor growth rather than tumor migration and invasion. The therapeutic efficiency of anti-cancer therapy is a critical factor affecting the long-term survival of cancer patients [50]. This suggested that CHRDL1 could predict patients who will be more conductive to anti-cancer therapy. Logistic regression also verified that CHRDL1 is a protective factor for LUAD patients in the above aspects. Noticeably, high levels of CHRDL1 are also a protective factor against TP53 mutations. As we known, TP53 is famous for a tumor suppressor gene, which plays an essential role in the maintenance of cell proliferation and apoptosis homeostasis [51]. The mutation of TP53 is one of the most common genetic mutations in cancers [52]. This may imply that CHRDL1 could affect the proliferation of tumor cells through TP53 mutations, just as we mentioned above affecting the $\mathrm{T}$ stage. Simultaneously, univariate and multivariate regression analysis suggested that CHRDL1 is an independent prognostic factor. Furthermore, the OS period of the high CHRDL1 group was significantly prolonged. The above results illustrated that CHRDL1 maybe a prognostic biomarker and possess promising prognostic value for LUAD patients.

The promising prognostic value of CHRDL1 makes us yearn for latent molecular mechanisms and regulatory networks. To further elucidate the relevant underlying cellular mechanisms of CHRDL1 in LUAD, GO and KEGG analysis were performed in subsequent study. Certainly, the results were consistent with previous studies. It was mainly related to biological process and pathway of secretion and nerve synapse, as CHRDL1 is a secretory protein and involved in neurodevelopment $[14,15]$. On the other hand, we also found that CHRDL1 was associated with maintenance of homeostasis and immune regulation, such as complement and coagulation system, body hormone synthesis and humoral immune response. In order for the above results to be confirmed more convincingly, GSEA analysis was performed. The results suggested that CHRDL1 was indeed related to the homeostasis of cell proliferation, such as cell cycle checkpoint, protein translation and G2M phase checkpoint. The cell cycle is almost the most vital pathway regulating proliferation of tumor cells [53]. Therefore, the abnormal decrease of CHRDL1 may cause the excessive proliferation of cancer cells through activation of cell cycle checkpoint. At present, cell cycle checkpoint inhibitors (ATR, CHK1 and WEE1) have been already an general and effective measure for anti-cancer therapy [54-56]. And the role of tumor suppressor TP53 in triggering cell cycle checkpoints has been confirmed [57]. The above findings indicated that CHRDL1 could serve as a potential therapy target on inhibiting the proliferation of LUAD cells by cell cycle checkpoint.

On the other hand, interestingly, we found that CHRDL1 has a certain relationship in in lymphocyte immunoregulatory interactions through GSEA analysis. The immunomodulatory function of CHRDL1 has not been reported yet. A recent clinical trial study found that tumour-infiltrating lymphocyte abundance is significantly correlative with promising outcome in patients with advanced NSCLC treated with immunotherapy [58]. This suggested that CHRDL1 may affect the efficiency of immunotherapy by regulating immune infiltration. Thus, we calculated the abundance correlation between 24 types of immune cells and CHRDL1 expression. Obviously, CHRDL1 expression significantly correlated with 7 kinds of immune cells. And most of them belong to innate immunity (mast cells, eosinophils, iDCs, DCs and macrophages). As we known, innate immunity is a natural barrier for human beings to foreign antigens and maintains the homeostasis [59-61]. Studies have shown that lack of innate immunity was an essential factor for the emergence and development of lung cancer [62]. This suggests that CHRDL1 may be able to protect our body against the invasion of cancer through innate immunity.

Lately, immunotherapy has emerged as a prospective treatment for [58]. But only a minority of cancer patients have benefited from immunotherapy successfully. Tumor-specific cytotoxic T lymphocytes (CTLs) have been regarded as a powerful method of antitumor immunotherapy $[63,64]$. Th1 cells appear to 
be essential for the optimum generation and the durability of specific CTLs [65]. In fact, Th2 cells always significantly limit current immunotherapy through negatively regulating Th1-type immunity [66]. Therefore, our study found that Th2 cells were negatively correlated with CHRDL1, whereas Th1 cells and CHRDL1 were positive correlated. This also explains why patients with low CHRDL1 expression had poor treatment outcome. The former studies suggested that CD30 was preferably expressed on CD4+ T cells, which produce Th2 cytokines [67, 68]. Thus, we indirectly confirmed a negative correlation between CHRDL1 and Th2 cells by immunohistochemical detection of CD30. These findings indicated that CHRDL1 might improve the effectiveness of immunotherapy in LUAD by regulating immune infiltration.

Although our study served as a precedent for elucidating the expression and prognostic value of CHRDL1 in LUAD, there are still some limitations. First of all, our validation of prognostic value of CHRDL1 was imperfect due to insufficient sample size and time limitation. For example, the sample did not include enough patients with distant metastasis, and the follow-up time was not long enough. So more clinical trials are needed to complete more adequate validation of prognostic value of CHRDL1 in the future. Second, although we discussed the possible mechanism of CHRDL1 in regulating LUAD, there are some deviations to using transcriptome to predict protein expression [69]. Thus, more wet experiments are required to identify the specific biological functions and regulatory mechanisms of CHRDL1 in LUAD.

In conclusion, our study demonstrated the expression and prognostic value of CHRDL1 in LUAD. CHRDL1 may be a potential therapy target through cell cycle checkpoint and improve the effectiveness of immunotherapy by regulating immune infiltration. Our study supplies novel and prospective insights for subsequent research to clarify the clinicopathological importance and molecular pathogenesis of LUAD.

\section{AUTHOR CONTRIBUTIONS}

DPJ and BD designed this research; BD completed the research and wrote the manuscript; XRC, LFX, LZ, XQZ, JWS, WZ and YD participated in data collection and arrangement. All authors have read and approved this manuscript for publication.

\section{CONFLICTS OF INTEREST}

The authors declare that they have no conflicts of interest.

\section{FUNDING}

This work was supported by Young and Middle-aged Senior Medical Talents studio of Chongqing, grant 2016HBRC004 from Chongqing Health Commission and grant cstc2018jcyjAX0115 from Chongqing Science and Technology Commission.

\section{REFERENCES}

1. Siegel RL, Miller KD, Jemal A. Cancer statistics, 2019. CA Cancer J Clin. 2019; 69:7-34. https://doi.org/10.3322/caac.21551 PMID:30620402

2. Cui $Y$, Zhang $S$, Miao $C$, Liang $C$, Chen $X$, Yan $T$, Bu H, Dong $\mathrm{H}$, Li J, Li J, Wang Z, Liu B. Identification of autophagy-related long non-coding RNA prognostic and immune signature for clear cell renal cell carcinoma. Transl Androl Urol. 2021; 10:3317-31. https://doi.org/10.21037/tau-21-278 PMID:34532256

3. DeSantis $C E$, Lin CC, Mariotto $A B$, Siegel $R L$, Stein $K D$, Kramer JL, Alteri R, Robbins AS, Jemal A. Cancer treatment and survivorship statistics, 2014. CA Cancer J Clin. 2014; 64:252-71. https://doi.org/10.3322/caac.21235 PMID:24890451

4. Osmani L, Askin F, Gabrielson E, Li QK. Current WHO guidelines and the critical role of immunohistochemical markers in the subclassification of non-small cell lung carcinoma (NSCLC): Moving from targeted therapy to immunotherapy. Semin Cancer Biol. 2018; 52:103-9.

https://doi.org/10.1016/j.semcancer.2017.11.019 PMID:29183778

5. Stella GM, Luisetti M, Pozzi E, Comoglio PM. Oncogenes in non-small-cell lung cancer: emerging connections and novel therapeutic dynamics. Lancet Respir Med. 2013; 1:251-61.

https://doi.org/10.1016/S2213-2600 (13)70009-2 PMID:24429131

6. Soda M, Choi YL, Enomoto M, Takada S, Yamashita Y, Ishikawa S, Fujiwara S, Watanabe H, Kurashina K, Hatanaka H, Bando M, Ohno S, Ishikawa $Y$, et al. Identification of the transforming EML4-ALK fusion gene in non-small-cell lung cancer. Nature. 2007; 448:561-6.

https://doi.org/10.1038/nature05945 PMID: 17625570

7. Shaw AT, Felip E, Bauer TM, Besse B, Navarro A, PostelVinay S, Gainor JF, Johnson M, Dietrich J, James LP, Clancy JS, Chen J, Martini JF, et al. Lorlatinib in nonsmall-cell lung cancer with ALK or ROS1 rearrangement: an international, multicentre, openlabel, single-arm first-in-man phase 1 trial. Lancet Oncol. 2017; 18:1590-9.

https://doi.org/10.1016/S1470-2045 (17)30680-0 PMID:29074098 
8. Ma W, Wang B, Zhang Y, Wang Z, Niu D, Chen S, Zhang Z, Shen N, Han W, Zhang X, Wei R, Wang C. Prognostic significance of TOP2A in non-small cell lung cancer revealed by bioinformatic analysis. Cancer Cell Int. 2019; 19:239.

https://doi.org/10.1186/s12935-019-0956-1

PMID:31528121

9. Croegaert K, Kolesar JM. Role of anaplastic lymphoma kinase inhibition in the treatment of non-small-cell lung cancer. Am J Health Syst Pharm. 2015; 72:1456-62.

https://doi.org/10.2146/ajhp140836

PMID:26294238

10. Testa U, Castelli G, Pelosi E. Lung Cancers: Molecular Characterization, Clonal Heterogeneity and Evolution, and Cancer Stem Cells. Cancers (Basel). 2018; 10:248. https://doi.org/10.3390/cancers10080248 PMID:30060526

11. Nanavaty P, Alvarez MS, Alberts WM. Lung cancer screening: advantages, controversies, and applications. Cancer Control. 2014; 21:9-14. https://doi.org/10.1177/107327481402100102 PMID:24357736

12. Sawala A, Sutcliffe C, Ashe HL. Multistep molecular mechanism for bone morphogenetic protein extracellular transport in the Drosophila embryo. Proc Natl Acad Sci USA. 2012; 109:11222-7. https://doi.org/10.1073/pnas.1202781109 PMID:22733779

13. Huang J, Wei X, Ma W, Yuan Z. The miR-532-3p/Chrdl1 axis regulates the proliferation and migration of amniotic fluid-derived mesenchymal stromal cells. Biochem Biophys Res Commun. 2020; 527:187-93. https://doi.org/10.1016/i.bbrc.2020.04.099 PMID:32446365

14. Gaughwin P, Ciesla M, Yang H, Lim B, Brundin P. Stagespecific modulation of cortical neuronal development by Mmu-miR-134. Cereb Cortex. 2011; 21:1857-69. https://doi.org/10.1093/cercor/bhq262 PMID:21228099

15. Webb TR, Matarin M, Gardner JC, Kelberman D, Hassan H, Ang W, Michaelides M, Ruddle JB, Pennell CE, Yazar S, Khor CC, Aung T, Yogarajah M, et al. Xlinked megalocornea caused by mutations in CHRDL1 identifies an essential role for ventroptin in anterior segment development. Am J Hum Genet. 2012; 90:247-59.

https://doi.org/10.1016/j.ajhg.2011.12.019 PMID:22284829

16. Mithani SK, Smith IM, Califano JA. Use of integrative epigenetic and cytogenetic analyses to identify novel tumor-suppressor genes in malignant melanoma. Melanoma Res. 2011; 21:298-307.
https://doi.org/10.1097/CMR.0b013e328344a003 PMID:21606880

17. Nagel S, Ehrentraut S, Meyer C, Kaufmann M, Drexler HG, MacLeod RA. Repressed BMP signaling reactivates NKL homeobox gene MSX1 in a T-ALL subset. Leuk Lymphoma. 2015; 56:480-91.

https://doi.org/10.3109/10428194.2014.924119 PMID:24844359

18. Cyr-Depauw C, Northey JJ, Tabariès S, Annis MG, Dong Z, Cory S, Hallett M, Rennhack JP, Andrechek ER, Siegel PM. Chordin-Like 1 Suppresses Bone Morphogenetic Protein 4-Induced Breast Cancer Cell Migration and Invasion. Mol Cell Biol. 2016; 36:1509-25. https://doi.org/10.1128/MCB.00600-15 PMID:26976638

19. Pei YF, Zhang YJ, Lei $Y$, Wu WD, Ma TH, Liu XQ. Hypermethylation of the CHRDL1 promoter induces proliferation and metastasis by activating Akt and Erk in gastric cancer. Oncotarget. 2017; 8:23155-66.

https://doi.org/10.18632/oncotarget.15513 PMID:28423564

20. Wang X, Gao C, Feng F, Zhuang J, Liu L, Li H, Liu C, Wu J, Zheng $X$, Ding $X$, Sun $C$. Construction and Analysis of Competing Endogenous RNA Networks for Breast Cancer Based on TCGA Dataset. Biomed Res Int. 2020; 2020:4078596.

https://doi.org/10.1155/2020/4078596

PMID:32775417

21. Shen Y, Dong S, Liu J, Zhang L, Zhang J, Zhou H, Dong W. Identification of Potential Biomarkers for Thyroid Cancer Using Bioinformatics Strategy: A Study Based on GEO Datasets. Biomed Res Int. 2020; 2020:9710421. https://doi.org/10.1155/2020/9710421 PMID: $\underline{32337286}$

22. Xia Z, Ou-Yang W, Hu T, Du K. Prognostic significance of CDC25C in lung adenocarcinoma: An analysis of TCGA data. Cancer Genet. 2019; 233-234:67-74. https://doi.org/10.1016/i.cancergen.2019.04.001 PMID:31109596

23. Vivian J, Rao AA, Nothaft FA, Ketchum C, Armstrong J, Novak A, Pfeil J, Narkizian J, Deran AD, MusselmanBrown A, Schmidt H, Amstutz P, Craft B, et al. Toil enables reproducible, open source, big biomedical data analyses. Nat Biotechnol. 2017; 35:314-6.

https://doi.org/10.1038/nbt.3772 PMID:28398314

24. Love MI, Huber W, Anders S. Moderated estimation of fold change and dispersion for RNA-seq data with DESeq2. Genome Biol. 2014; 15:550. https://doi.org/10.1186/s13059-014-0550-8 PMID:25516281 
25. Yu G, Wang LG, Han Y, He QY. clusterProfiler: an R package for comparing biological themes among gene clusters. OMICS. 2012; 16:284-7.

https://doi.org/10.1089/omi.2011.0118

PMID:22455463

26. Subramanian A, Tamayo $P$, Mootha VK, Mukherjee $S$, Ebert BL, Gillette MA, Paulovich A, Pomeroy SL, Golub TR, Lander ES, Mesirov JP. Gene set enrichment analysis: a knowledge-based approach for interpreting genome-wide expression profiles. Proc Natl Acad Sci USA. 2005; 102:15545-50.

https://doi.org/10.1073/pnas.0506580102

PMID:16199517

27. Lv L, Zhang Y, Zhao Y, Wei Q, Zhao Y, Yi Q. Effects of $1 p / 19 q$ Codeletion on Immune Phenotype in Low Grade Glioma. Front Cell Neurosci. 2021; 15:704344. https://doi.org/10.3389/fncel.2021.704344 PMID:34335194

28. Feng $X$, Tang $R$, Zhang $R$, Wang $H$, Ji Z, Shao $Y$, Wang $S$, Zhong T, Gu Y, Meng J. A comprehensive analysis of IDO1 expression with tumour-infiltrating immune cells and mutation burden in gynaecologic and breast cancers. J Cell Mol Med. 2020; 24:5238-48.

https://doi.org/10.1111/jcmm.15176

PMID: $\underline{32227579}$

29. Zhang W, Liu Z, Xia S, Yao L, Li L, Gan Z, Tang H, Guo Q, Yan X, Sun Z. GDI2 is a novel diagnostic and prognostic biomarker in hepatocellular carcinoma. Aging (Albany NY). 2021; 13:25304-24.

https://doi.org/10.18632/aging.203748

PMID:34894398

30. Yang $S$, Wu $Y$, Wang $S$, Xu P, Deng $Y$, Wang $M$, Liu K, Tian T, Zhu Y, Li N, Zhou L, Dai Z, Kang H. HPV-related methylation-based reclassification and risk stratification of cervical cancer. Mol Oncol. 2020; 14:2124-41.

https://doi.org/10.1002/1878-0261.12709

PMID:32408396

31. Bindea G, Mlecnik B, Tosolini M, Kirilovsky A, Waldner $M$, Obenauf $A C$, Angell $H$, Fredriksen $T$, Lafontaine $L$, Berger A, Bruneval P, Fridman WH, Becker C, et al. Spatiotemporal dynamics of intratumoral immune cells reveal the immune landscape in human cancer. Immunity. 2013; 39:782-95.

https://doi.org/10.1016/i.immuni.2013.10.003

PMID:24138885

32. Szklarczyk D, Gable AL, Lyon D, Junge A, Wyder S, Huerta-Cepas J, Simonovic M, Doncheva NT, Morris JH, Bork P, Jensen L, Mering CV. STRING v11: proteinprotein association networks with increased coverage, supporting functional discovery in genome-wide experimental datasets. Nucleic Acids Res. 2019; 47:D607-13. https://doi.org/10.1093/nar/gky1131

PMID:30476243

33. Liu J, Lichtenberg T, Hoadley KA, Poisson LM, Lazar AJ, Cherniack AD, Kovatich AJ, Benz CC, Levine DA, Lee AV, Omberg L, Wolf DM, Shriver CD, et al, and Cancer Genome Atlas Research Network. An Integrated TCGA Pan-Cancer Clinical Data Resource to Drive HighQuality Survival Outcome Analytics. Cell. 2018; 173:400-16.e11.

https://doi.org/10.1016/i.cell.2018.02.052 PMID:29625055

34. Robin X, Turck N, Hainard A, Tiberti N, Lisacek F, Sanchez JC, Müller M. pROC: an open-source package for $\mathrm{R}$ and $\mathrm{S}+$ to analyze and compare ROC curves. BMC Bioinformatics. 2011; 12:77. https://doi.org/10.1186/1471-2105-12-77 PMID:21414208

35. Liang $\mathrm{H}$, Hao XS, Wang $\mathrm{P}$, Wang XN, Li JW, Wang JC, Wang DC. [Multivariate Cox analysis on prognostic factors after surgery for rectal carcinoma]. Zhonghua Zhong Liu Za Zhi. 2004; 26:688-91.

PMID:15777510

36. Lubke GH, Campbell I, McArtor D, Miller P, Luningham J, van den Berg SM. Assessing Model Selection Uncertainty Using a Bootstrap Approach: An update. Struct Equ Modeling. 2017; 24:230-45. https://doi.org/10.1080/10705511.2016.1252265 PMID:28652682

37. Wei C, Gao Y, Chen X, Zhao C, Li P. ZNF668: a new diagnostic predictor of kidney renal clear cell carcinoma. Anticancer Drugs. 2022; 33:e491-9. https://doi.org/10.1097/CAD.0000000000001149 PMID:34261923

38. Li E, Luo T, Wang Y. Identification of diagnostic biomarkers in patients with gestational diabetes mellitus based on transcriptome gene expression and methylation correlation analysis. Reprod Biol Endocrinol. 2019; 17:112. https://doi.org/10.1186/s12958-019-0556-x PMID:31881887

39. Chen J, Xie C, Zhao Y, Li Z, Xu P, Yao L. Gene expression analysis reveals the dysregulation of immune and metabolic pathways in Alzheimer's disease. Oncotarget. 2016; 7:72469-74.

https://doi.org/10.18632/oncotarget.12505 PMID:27732949

40. Prieto C, Risueño A, Fontanillo C, De las Rivas J. Human gene coexpression landscape: confident network derived from tissue transcriptomic profiles. PLoS One. 2008; 3:e3911. https://doi.org/10.1371/journal.pone.0003911 PMID:19081792 
41. Nakayama N, Han CE, Scully S, Nishinakamura R, He C, Zeni L, Yamane H, Chang D, Yu D, Yokota T, Wen D. A novel chordin-like protein inhibitor for bone morphogenetic proteins expressed preferentially in mesenchymal cell lineages. Dev Biol. 2001; 232:372-87. https://doi.org/10.1006/dbio.2001.0200 PMID:11401399

42. Kane R, Godson C, O'Brien C. Chordin-like 1, a bone morphogenetic protein-4 antagonist, is upregulated by hypoxia in human retinal pericytes and plays a role in regulating angiogenesis. Mol Vis. 2008; 14:1138-48. PMID: 18587495

43. Gao WL, Zhang SQ, Zhang H, Wan B, Yin ZS. Chordinlike protein 1 promotes neuronal differentiation by inhibiting bone morphogenetic protein-4 in neural stem cells. Mol Med Rep. 2013; 7:1143-8.

https://doi.org/10.3892/mmr.2013.1310 PMID:23404565

44. Pfirrmann T, Emmerich D, Ruokonen $P$, Quandt $D$, Buchen R, Fischer-Zirnsak B, Hecht J, Krawitz P, Meyer P, Klopocki E, Stricker S, Lausch E, Seliger B, et al. Molecular mechanism of CHRDL1-mediated X-linked megalocornea in humans and in Xenopus model. Hum Mol Genet. 2015; 24:3119-32.

https://doi.org/10.1093/hmg/ddv063 PMID:25712132

45. Fang $W T$, Fan CC, Li SM, Jang TH, Lin HP, Shih NY, Chen $\mathrm{CH}$, Wang TY, Huang SF, Lee AY, Liu YL, Tsai FY, Huang CT, et al. Downregulation of a putative tumor suppressor BMP4 by SOX2 promotes growth of lung squamous cell carcinoma. Int J Cancer. 2014; 135:809-19.

https://doi.org/10.1002/ijc.28734 PMID:24477565

46. Kim JS, Kurie JM, Ahn YH. BMP4 depletion by miR-200 inhibits tumorigenesis and metastasis of lung adenocarcinoma cells. Mol Cancer. 2015; 14:173.

https://doi.org/10.1186/s12943-015-0441-y PMID:26395571

47. Donehower LA, Soussi T, Korkut A, Liu Y, Schultz A, Cardenas M, Li X, Babur O, Hsu TK, Lichtarge O, Weinstein JN, Akbani R, Wheeler DA. Integrated Analysis of TP53 Gene and Pathway Alterations in The Cancer Genome Atlas. Cell Rep. 2019; 28:1370-84.e5. https://doi.org/10.1016/j.celrep.2019.07.001 PMID:31365877

48. Zheng MJ, Li X, Hu YX, Dong $H$, Gou R, Nie X, Liu Q, Ying-Ying $\mathrm{H}$, Liu JJ, Lin B. Identification of molecular marker associated with ovarian cancer prognosis using bioinformatics analysis and experiments. J Cell Physiol. 2019; 234:11023-36.

https://doi.org/10.1002/jcp.27926 PMID:30633343

49. Hwang JK, Page BJ, Flynn D, Passmore L, McCaul E, Brady J, Yang IA, Marshall H, Windsor M, Bowman RV,
Naidoo R, Guan T, Philpot S, et al. Validation of the Eighth Edition TNM Lung Cancer Staging System. J Thorac Oncol. 2020; 15:649-54.

https://doi.org/10.1016/j.jtho.2019.11.030

PMID:31863848

50. Chiao EY, Coghill A, Kizub D, Fink V, Ndlovu N, Mazul A, Sigel K. The effect of non-AIDS-defining cancers on people living with HIV. Lancet Oncol. 2021; 22:e240-53. https://doi.org/10.1016/S1470-2045 (21)00137-6 PMID:34087151

51. Hafner A, Bulyk ML, Jambhekar A, Lahav G. The multiple mechanisms that regulate p53 activity and cell fate. Nat Rev Mol Cell Biol. 2019; 20:199-210. https://doi.org/10.1038/s41580-019-0110-x PMID:30824861

52. Levine AJ. p53: 800 million years of evolution and 40 years of discovery. Nat Rev Cancer. 2020; 20:471-80. https://doi.org/10.1038/s41568-020-0262-1 PMID: $\underline{32404993}$

53. Hanahan D, Weinberg RA. Hallmarks of cancer: the next generation. Cell. 2011; 144:646-74.

https://doi.org/10.1016/i.cell.2011.02.013 PMID:21376230

54. Ghelli Luserna di Rora' A, lacobucci I, Martinelli G. The cell cycle checkpoint inhibitors in the treatment of leukemias. J Hematol Oncol. 2017; 10:77.

https://doi.org/10.1186/s13045-017-0443-x PMID:28356161

55. Friedman J, Morisada M, Sun L, Moore EC, Padget $M$, Hodge JW, Schlom J, Gameiro SR, Allen CT. Inhibition of WEE1 kinase and cell cycle checkpoint activation sensitizes head and neck cancers to natural killer cell therapies. J Immunother Cancer. 2018; 6:59.

https://doi.org/10.1186/s40425-018-0374-2 PMID:29925431

56. Chung S, Vail P, Witkiewicz AK, Knudsen ES. Coordinately Targeting Cell-Cycle Checkpoint Functions in Integrated Models of Pancreatic Cancer. Clin Cancer Res. 2019; 25:2290-304.

https://doi.org/10.1158/1078-0432.CCR-18-1620 PMID:30538111

57. Cannell IG, Merrick KA, Morandell S, Zhu CQ, Braun CJ, Grant RA, Cameron ER, Tsao MS, Hemann MT, Yaffe MB. A Pleiotropic RNA-Binding Protein Controls Distinct Cell Cycle Checkpoints to Drive Resistance of p53-Defective Tumors to Chemotherapy. Cancer Cell. 2015; 28:623-37.

https://doi.org/10.1016/i.ccell.2015.09.009 PMID:26602816

58. Gataa I, Mezquita L, Rossoni C, Auclin E, Kossai M, Aboubakar F, Le Moulec S, Massé J, Masson M, Radosevic-Robin N, Alemany P, Rouanne M, Bluthgen 
$V$, et al. Tumour-infiltrating lymphocyte density is associated with favourable outcome in patients with advanced non-small cell lung cancer treated with immunotherapy. Eur J Cancer. 2021; 145:221-9.

https://doi.org/10.1016/j.ejca.2020.10.017

PMID:33516050

59. Roeen Z, Toda M, D’Alessandro-Gabazza CN, Onishi M, Kobayashi T, Yasuma T, Urawa M, Taguchi O, Gabazza EC. Thrombomodulin inhibits the activation of eosinophils and mast cells. Cell Immunol. 2015; 293:34-40.

https://doi.org/10.1016/i.cellimm.2014.11.005 PMID:25497974

60. Devi KS, Anandasabapathy N. The origin of DCs and capacity for immunologic tolerance in central and peripheral tissues. Semin Immunopathol. 2017; 39:137-52.

https://doi.org/10.1007/s00281-016-0602-0

PMID:27888331

61. DeNardo DG, Ruffell B. Macrophages as regulators of tumour immunity and immunotherapy. Nat Rev Immunol. 2019; 19:369-82.

https://doi.org/10.1038/s41577-019-0127-6

PMID:30718830

62. Zhang $Y$, Zhang $Z$. The history and advances in cancer immunotherapy: understanding the characteristics of tumor-infiltrating immune cells and their therapeutic implications. Cell Mol Immunol. 2020; 17:807-21. https://doi.org/10.1038/s41423-020-0488-6 PMID:32612154

63. Liu L, Dai B, Li R, Liu Z, Zhang Z. Intravital molecular imaging reveals the restrained capacity of CTLs in the killing of tumor cells in the liver. Theranostics. 2021; 11:194-208. https://doi.org/10.7150/thno.44979 PMID:33391470

64. Zhao P, Bu X, Wei X, Sun W, Xie X, Li C, Guo Q, Zhu D, Wei $X$, Gao D. Dendritic cell immunotherapy combined with cytokine-induced killer cells promotes skewing toward Th2 cytokine profile in patients with metastatic non-small cell lung cancer. Int Immunopharmacol. 2015; 25:450-6.

https://doi.org/10.1016/j.intimp.2015.02.010

PMID:25698555

65. Hong S, Qian J, Yang J, Li H, Kwak LW, Yi Q. Roles of idiotype-specific $t$ cells in myeloma cell growth and survival: Th1 and CTL cells are tumoricidal while Th2 cells promote tumor growth. Cancer Res. 2008; 68:8456-64.

https://doi.org/10.1158/0008-5472.CAN-08-2213 PMID:18922919

66. Basu A, Ramamoorthi G, Albert G, Gallen C, Beyer A, Snyder C, Koski G, Disis ML, Czerniecki BJ, Kodumudi K. Differentiation and Regulation of $\mathrm{T}_{\mathrm{H}}$ Cells: A Balancing Act for Cancer Immunotherapy. Front Immunol. 2021; 12:669474.

https://doi.org/10.3389/fimmu.2021.669474

PMID:34012451

67. Romagnani S, Del Prete G, Maggi E, Chilosi M, CaligarisCappio F, Pizzolo G. CD30 and type 2 T helper (Th2) responses. J Leukoc Biol. 1995; 57:726-30. https://doi.org/10.1002/ilb.57.5.726 PMID:7759952

68. Oflazoglu E, Grewal IS, Gerber H. Targeting CD30/CD30L in oncology and autoimmune and inflammatory diseases. Adv Exp Med Biol. 2009; 647:174-85.

https://doi.org/10.1007/978-0-387-89520-8 12 PMID:19760074

69. Guo Y, Xiao P, Lei S, Deng F, Xiao GG, Liu Y, Chen X, Li L, Wu $\mathrm{S}$, Chen $\mathrm{Y}$, Jiang $\mathrm{H}$, Tan $\mathrm{L}$, Xie J, et al. How is mRNA expression predictive for protein expression? A correlation study on human circulating monocytes. Acta Biochim Biophys Sin (Shanghai). 2008; 40:426-36. https://doi.org/10.1111/i.1745-7270.2008.00418.x PMID:18465028 


\section{SUPPLEMENTARY MATERIALS}

\section{Supplementary Figures}

A

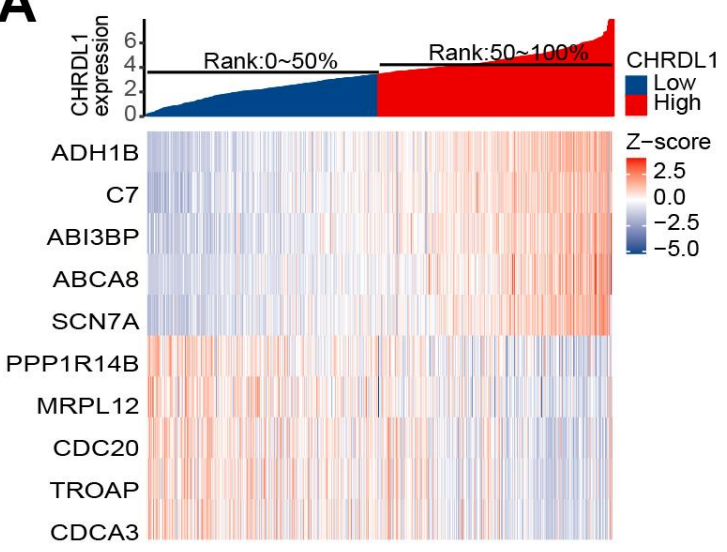

B

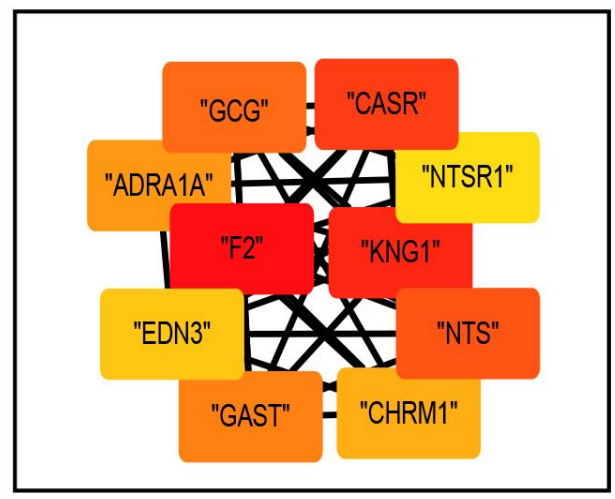

C

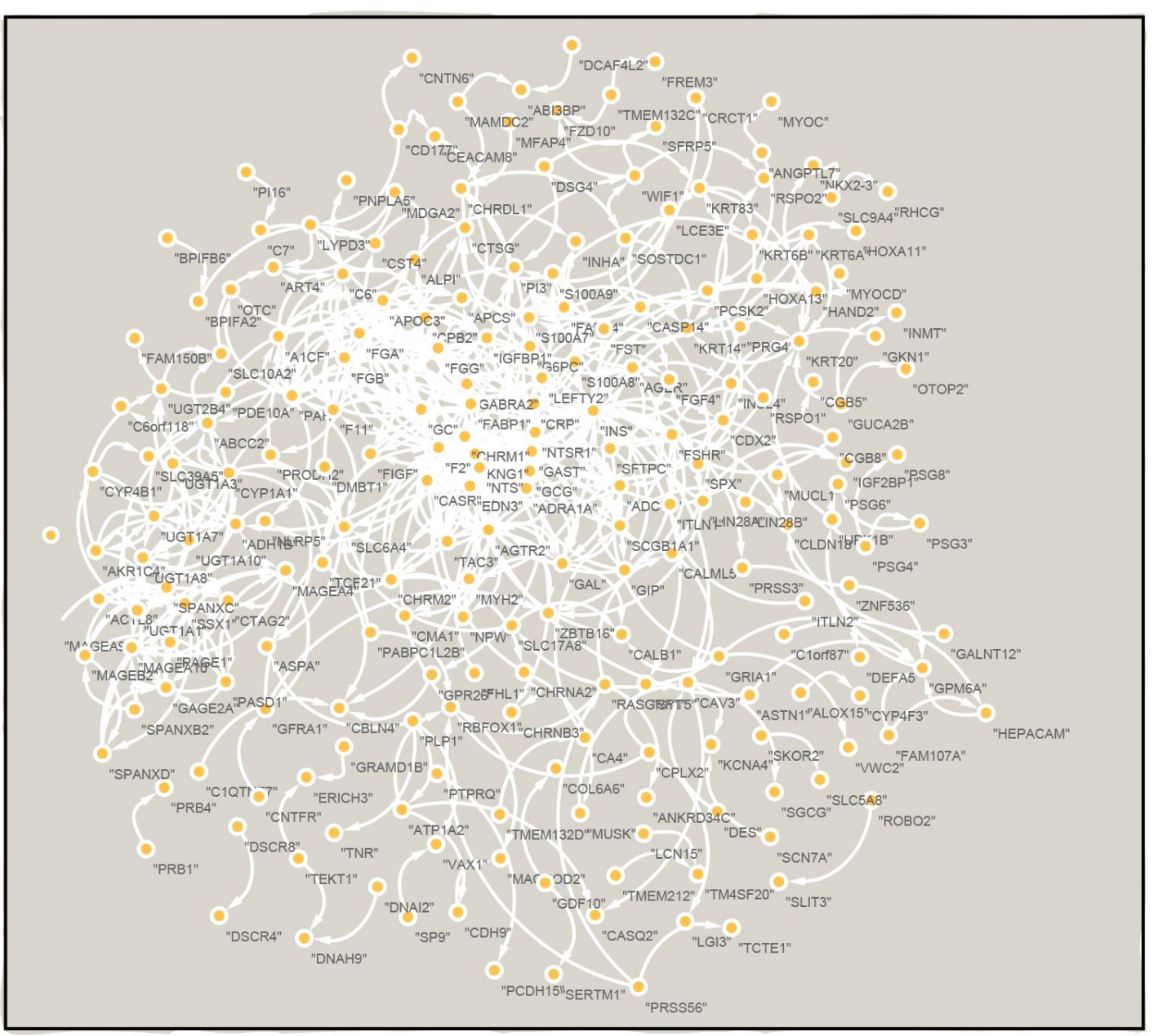

Supplementary Figure 1. Establishment of protein-protein interaction (PPI) network. (A) Heat map of CHRDL1 related coexpressed genes. (B) CHRDL1 related hub genes screened by Hubba plug-in algorithm of Cytoscape. (C) Establishment of protein-protein interaction (PPI) network based on CHRDL1. 

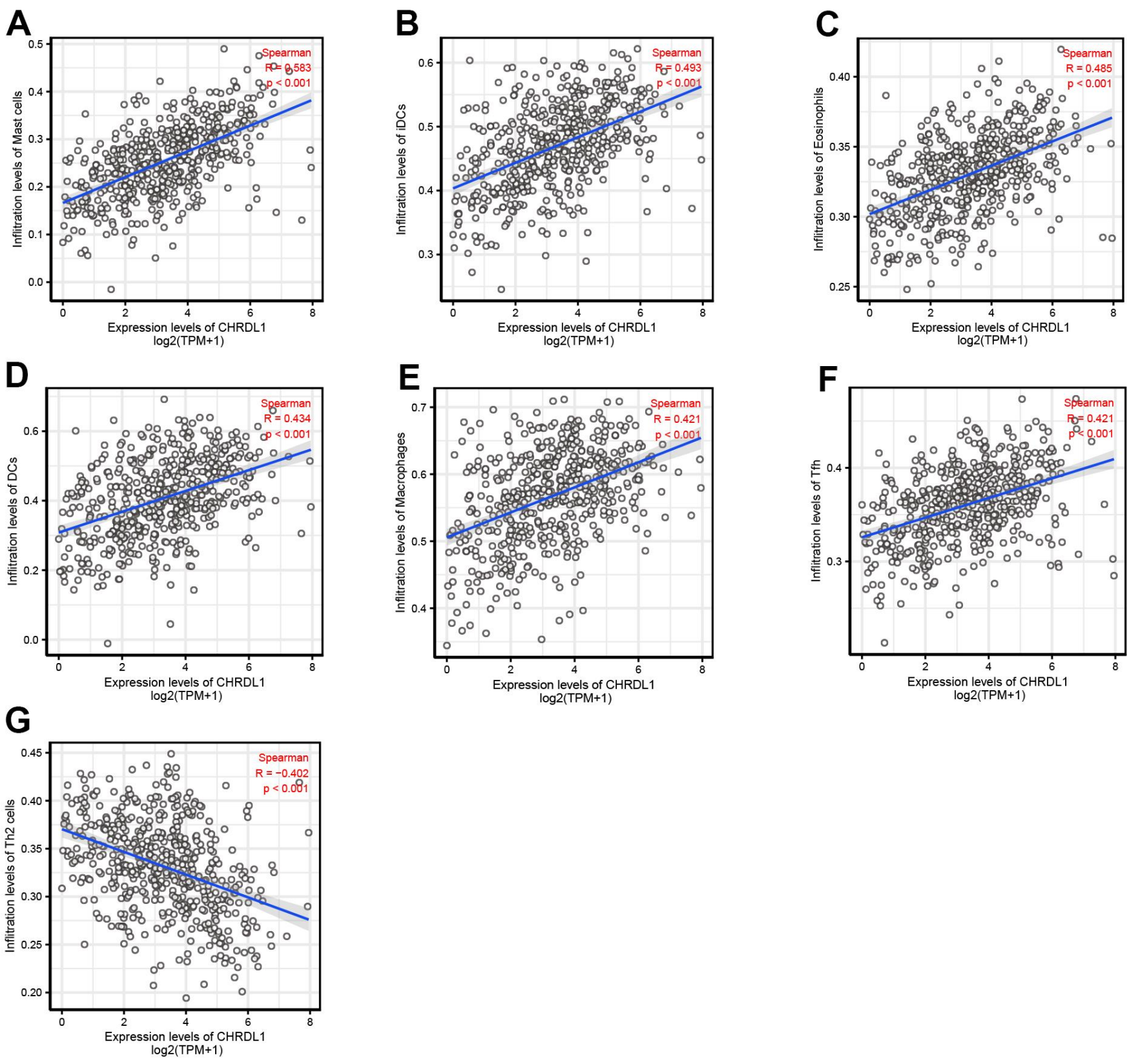

Supplementary Figure 2. The expression of CHRDL1 was significantly correlated with the infiltration level of 7 kinds of immune cells, including (A-G): Mast cells, iDCs, Eosinophils, DCs, Macrophages, Tfh and Th2 cells. 